\title{
OPEN Structural and optical properties of amorphous Si-Ge-Te thin films prepared by combinatorial sputtering
}

\author{
C. Mihai ${ }^{1}$, F. Sava ${ }^{1}$, I. D. Simandan ${ }^{1}$, A. C. Galca ${ }^{1}$, I. Burducea ${ }^{2}$, N. Becherescu ${ }^{3}$ \& A. Velea ${ }^{1 凶}$
}

The lack of order in amorphous chalcogenides offers them novel properties but also adds increased challenges in the discovery and design of advanced functional materials. The amorphous compositions in the Si-Ge-Te system are of interest for many applications such as optical data storage, optical sensors and Ovonic threshold switches. But an extended exploration of this system is still missing. In this study, magnetron co-sputtering is used for the combinatorial synthesis of thin film libraries, outside the glass formation domain. Compositional, structural and optical properties are investigated and discussed in the framework of topological constraint theory. The materials in the library are classified as stressed-rigid amorphous networks. The bandgap is heavily influenced by the Te content while the near-IR refractive index dependence on Ge concentration shows a minimum, which could be exploited in applications. A transition from a disordered to a more ordered amorphous network at 60 at\% Te, is observed. The thermal stability study shows that the formed crystalline phases are dictated by the concentration of $\mathrm{Ge}$ and Te. New amorphous compositions in the $\mathrm{Si}-\mathrm{Ge}-\mathrm{Te}$ system were found and their properties explored, thus enabling an informed and rapid material selection and design for applications.

Amorphous chalcogenides possess unique properties that enable a broad range of applications in phase change memories ${ }^{1}(\mathrm{PCM})$, Ovonic threshold switches (selectors) ${ }^{2}$, solar cells ${ }^{3}$, or photonics ${ }^{4}$.

Amorphous materials structure lacks long-range translational order ${ }^{5}$. The term "amorphous" is generally used for non-crystalline solids that are obtained as thin films, flakes, nanoparticles by bottom-up approach (condensation of vapors on a cold substrate), or as powders by grinding the material in a ball mill. On the other hand, glasses are defined as those non-crystalline materials obtained by rapid solidification of their melt ${ }^{6}$, or, according to Phillips ${ }^{7}$ and Elliott ${ }^{8}$, as non-crystalline solids which have a glass transition.

Chalcogens are the chemical elements S, Se or Te, which belong to the group VI A (16) in the periodic table. Tellurium has a more pronounced metallic character and quite isotropic atomic bonds as opposed to the lighter chalcogens (selenium and sulfur). Therefore, tellurides are poor glass formers with an increased tendency towards crystallization or decomposition ${ }^{9}$. They display a reduced glass formation domain (GFD $)^{10}$ or no GFD at all, leading to crystallization of the melts upon cooling ${ }^{11}$. Amorphous chalcogenides are in quasi-equilibrium or meta-stable ${ }^{12}$ states, which means that their properties cannot be uniquely determined thermodynamically by temperature and pressure, because they change with time. It is considered that after infinitely long storage, the amorphous material relaxes into the corresponding crystal. Therefore, material properties are dependent upon the preparation method, synthesis conditions and prehistory.

The disordered structure and covalent bonding enable the continuous compositional variation, leading to a huge number of possible compositions but also to different properties for a fixed composition. Hence, there is a vast combinatorial space which requires the use of high-throughput ${ }^{13}$ combinatorial preparation and measurement methods for appropriate exploration.

Combinatorial depositions have been employed lately for materials discovery and optimization in different fields such as sensors ${ }^{14}$, photovoltaics ${ }^{15}$, thermoelectrics ${ }^{16}$, inorganic ${ }^{17}$ and functional materials ${ }^{18}$. Several deposition techniques like magnetron co-sputtering ${ }^{19-21}$, chemical bath deposition ${ }^{22}$ or pulsed laser deposition ${ }^{16}$ are suitable to obtain material libraries. Magnetron co-sputtering is used for the combinatorial synthesis of materials

${ }^{1}$ National Institute of Materials Physics, 077125 Magurele, Romania. ${ }^{2}$ Horia Hulubei National Institute of Physics and Nuclear Engineering, 077125 Magurele, Romania. ${ }^{3}$ Apel Laser Ltd., Vanatorilor 25, 077135 Mogosoaia, Romania. ${ }^{\boxplus}$ email: alin.velea@infim.ro 
libraries because it can cover a large compositional area in a single deposition ${ }^{23}$ and offers good atomic mixing. A key feature of this method is the possibility to obtain amorphous thin film compositions which are located beyond the GFD of bulk glasses ${ }^{24}$. An increased mobility in the surface layers is obtained when magnetron sputtering deposition takes place on substrates at a temperature around $85 \%$ of the glass transition temperature $\left(\mathrm{T}_{\mathrm{g}}\right)$. This allows for local atomic configurations that are not reachable by melt-quenching techniques and leads to the formation of very stable amorphous compositions ${ }^{25}$, which according to molecular dynamics simulations of melt quenching would require thousands of years of annealing ${ }^{26,27}$.

The $\mathrm{Si}-\mathrm{Ge}-\mathrm{Te}$ amorphous system has been little studied in literature. Feltz et al. ${ }^{28}$ found the GFD of this system near the tie line between $\mathrm{GeTe}_{4}$ and $\mathrm{SiTe}_{4}$. Some specific compositions such as $\mathrm{Si}_{15} \mathrm{Ge}_{11} \mathrm{Te}_{74}$ were identified as promising candidates for $\mathrm{PCM}^{29}$. Moreover, a possible link between the electrical properties and the flexible nature of the amorphous network was suggested ${ }^{30}$.

More recent studies ${ }^{2,31}$, are focused only on limited regions or tie-lines (i.e. $\mathrm{Si}_{\mathrm{x}}\left(\mathrm{GeTe}_{6}\right)_{1-\mathrm{x}}$ or $\mathrm{Ge}_{\mathrm{x}} \mathrm{Si}_{\mathrm{x}} \mathrm{Te}_{1-2 \mathrm{x}}$ ) inside the GFD. In $\mathrm{Si}_{\mathrm{x}}\left(\mathrm{GeTe}_{6}\right)_{1-\mathrm{x}}{ }^{2}$, the addition of $\mathrm{Si}$ to $\mathrm{GeTe}_{6}$ produces an increase in the crystallization temperature and a transition from Ovonic threshold switching to Ovonic memory switching with a higher threshold voltage. For $\mathrm{Ge}_{\mathrm{x}} \mathrm{Si}_{\mathrm{x}} \mathrm{Te}_{1-2 \mathrm{x}}{ }^{31}$, the existence of an intermediate phase between 7.5 at $\%<\mathrm{x}<9$ at $\%$ is of interest for PCM, because for these compositions properties such as resistivity or optical contrast remain unchanged. No studies on extended regions outside GFD were performed so far.

In this study, we explore the compositional, structural and optical properties of the $\mathrm{Si}-\mathrm{Ge}-\mathrm{Te}$ amorphous system, beyond the GFD, by focusing on the variation of Te concentration on a large compositional interval. A combinatorial approach through magnetron co-sputtering for materials library synthesis is employed. To our knowledge this is the most extensive study in the $\mathrm{Si}-\mathrm{Ge}-\mathrm{Te}$ ternary chalcogenide system with respect to the covered range of compositions. Rutherford backscattering (RBS), grazing incidence X-ray diffraction (GIXRD) and spectroscopic ellipsometry have been used to map the properties of the resulting library. Also, annealing was employed for thermal stability analysis.

\section{Results and discussion}

Chemical composition of the combinatorial chalcogenide library. The combinatorial Si-Ge-Te library was deposited on 24 substrates using three sets of magnetron co-sputtering depositions. The library has the following compositional spread by element: $[8.1 \div 45.6]$ at $\%$ for $\mathrm{Si},[16 \div 62.5]$ at $\%$ for $\mathrm{Ge}$ and $[15 \div 69.8]$ at $\%$ for Te. In comparison with other studies of the $\mathrm{Si}-\mathrm{Ge}-\mathrm{Te}$ system ${ }^{28,30,31}$, our new compositional domain is at least 5 times larger. An example of the concentration gradient from one deposition is given in Fig. 1b-d. The atomic composition is measured by RBS in the center of each sample with measurement uncertainty of less than 3 at $\%$. The full composition map is obtained by spatial interpolation using a Locally Weighted Regression model ${ }^{32}$. Each point is estimated by fitting a low degree polynomial on a subset of the data, giving more weight to the points near the estimated point.

The thickness of the samples (Fig. 1a) is dependent on the deposition time and on the distance from the sputtering targets. The minimum thickness is $299.8 \mathrm{~nm}$ for $\mathrm{Si}_{17.5} \mathrm{Ge}_{19.7} \mathrm{Te}_{62.8}$ and the maximum is $570.5 \mathrm{~nm}$ for $\mathrm{Si}_{14.9} \mathrm{Ge}_{26.3} \mathrm{Te}_{58.8}$. The samples closest to the Te target are thicker due to the increased deposition rate for Te as compared with $\mathrm{Si}$ and Ge. The thickness of all the samples in the library, determined by spectroscopic ellipsometry, is given in Table 1. Both thickness and compositional lateral gradients are expected on each sample.

Amorphous Si-Ge-Te formation domain. The glass formation domain (GFD) contains compositions that can be easily obtained in the bulk glassy state. The GFD of a system is usually mapped out systematically by sintering many samples of specific compositions which are reacted, quenched and then their crystalline or glassy phase is determined. The extent of GFD is dependent on the reacting temperature from which the melt is quenched, the quenching rate and the amount of material used in the sample preparation. For chalcogenide glasses it was shown that the glass-forming ability varies in the following order: $\mathrm{S}>\mathrm{Se}>\mathrm{Te}^{33}$. It was observed that near the border line of these domains one may find compositions with memory-switching properties ${ }^{34}$ (i.e. phase-change materials) or compositions with special thermal properties ${ }^{35}$ (i.e. intermediate phases).

In this study new amorphous $\mathrm{Si}-\mathrm{Ge}-\mathrm{Te}$ compositions are sought, so, the compositional space outside the GFD known from literature, is explored. The chemical composition of the 24 samples in the library, together with the GFD found by A. Feltz et al..$^{28}$ are shown in the ternary diagram from Fig. 2.

The GIXRD measurements (data not shown) reveal that all the samples have amorphous structure.

Topological constraint theory. Topological constraint theory ${ }^{36,37}$ classifies amorphous networks into flexible and rigid. The strong covalent bonds determine the local atomic structure of the disordered materials. In covalent solids, each atom supports two types of bonding constraints: bond-stretching constraints and bondbending constraints. In an amorphous covalent network, the average number of bond-stretching $\left(n_{B S}\right)$ and the average number of bond-bending $\left(n_{B B}\right)$ constraints per atom (averaged over all chemical elements of the material) can be computed using the average coordination number $(\langle r\rangle)$ over all atoms in the amorphous covalent network: $n_{B S}=<r>/ 2$ and $n_{B B}=2<r>-3$. If the average number of constraints per atom, $n_{c}\left(n_{c}=n_{B S}+n_{B B}\right)$, in an amorphous covalent material, is less than $3(<r><2.4)$, its network is considered flexible, the bonds between atoms are very flexible and the material is unstable because of entropy. If $n_{c}$ is greater than $3(<r>>2.4)$, the network is stressed-rigid, the atomic bonds are very rigid, and the amorphous covalent material is unstable because of strain. When $n_{c}=3(<r>=2.4)$, which is equal to the number of degrees of freedom per atom in three dimensions, the network is called isostatic, and the amorphous covalent material is stable.

Amorphous chalcogenides are mostly covalently bonded, which allows for the continuous variation of their composition in atomic ratios, rather than in chemical units as in the case of oxides, which have more ionic bonds. 

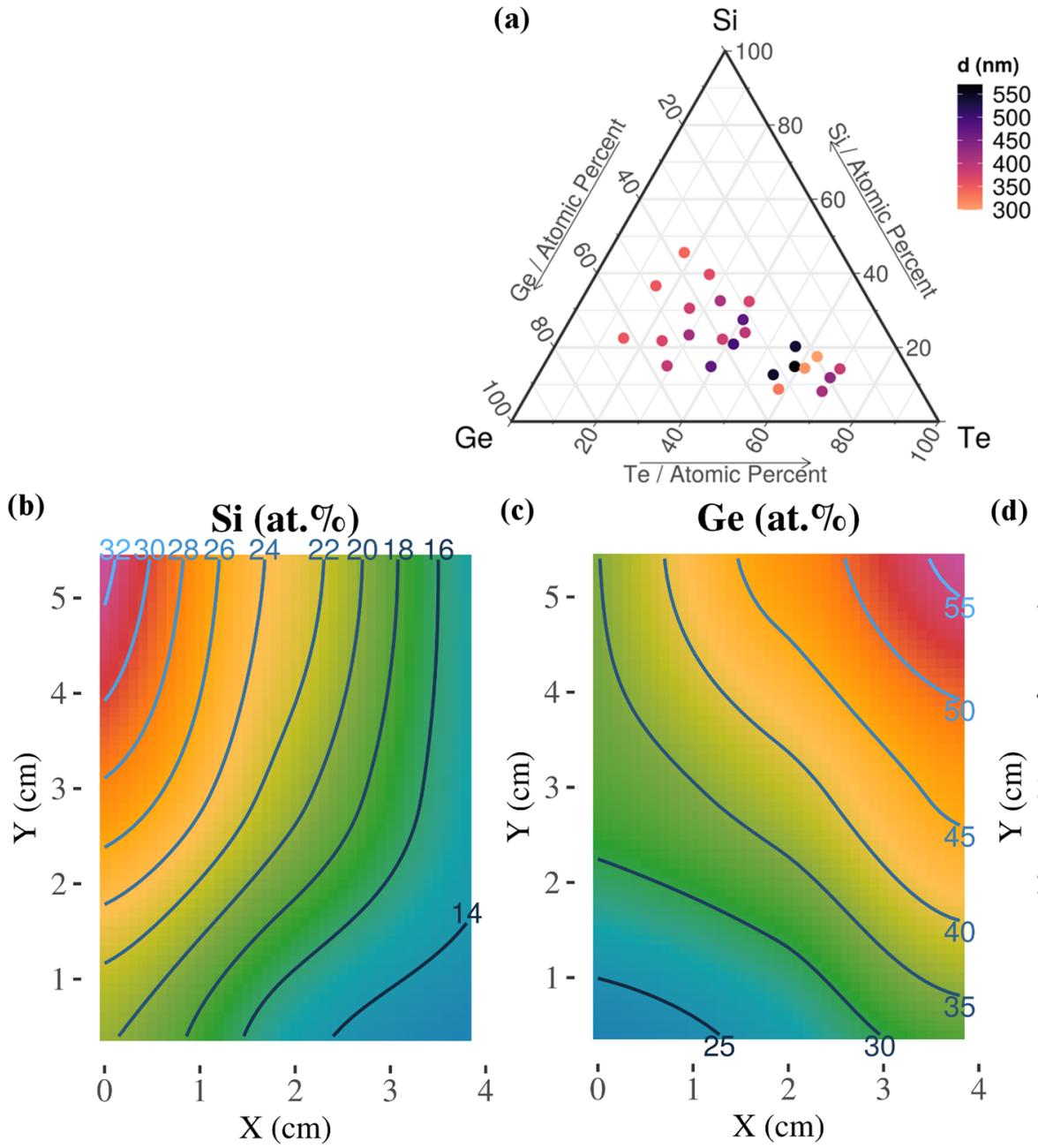

(c)

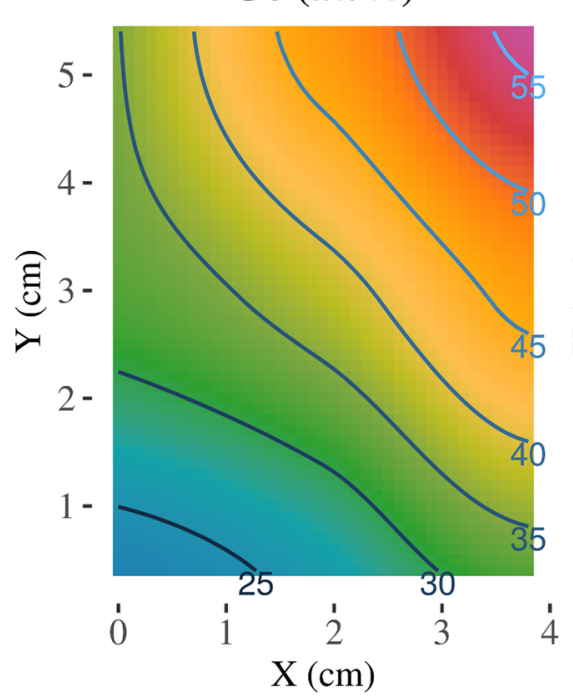

(d)

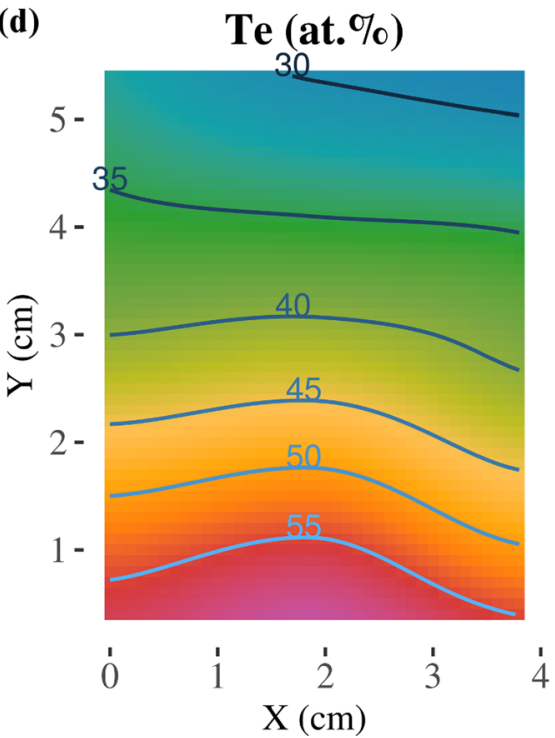

Figure 1. The chemical composition and thickness of the combinatorial chalcogenide library. (a) Thickness $(d)$ distribution (measured by spectroscopic ellipsometry) in the center of the 24 samples; Elemental concentration gradient in one representative deposition for (b) Si; (c) Ge; (d) Te. The ternary diagram in (a) was generated with the R software [v. 3.6.3] (R: A language and environment for statistical computing, R Core Team, $\mathrm{R}$ Foundation for Statistical Computing, Vienna, Austria (2020) http://www.R-project.org/.) using the package ggtern [v. 3.3.0] (https://cran.r-project.org/web/packages/ggtern/index.html).

The average coordination number $<r>$ per atom, is a simple yet powerful topological descriptor for understanding the compositional variation in amorphous chalcogenides. We notice however, that this descriptor does not take into account the chemical nature of bonds or the medium-range order. As an example, for the $\mathrm{Si}_{\mathrm{x}} \mathrm{Ge}_{\mathrm{y}} \mathrm{Te}_{1-\mathrm{x}-\mathrm{y}}$ composition, $\langle r>$ is computed as $[4 x+4 y+2(1-x-y)]$, considering that $\mathrm{Ge}$ and $\mathrm{Si}$ are fourfold coordinated and Te is twofold coordinated, according to the " $8-N$ rule" ( $N$ being the number of outer shell electrons). However, for Te-based compositions, the average coordination number might not be an accurate descriptor due to the metallic character of Tellurium, whose coordination number $\left(\mathrm{n}_{\mathrm{Te}}\right)$ can deviate from the $8-N$ rule $\left(\mathrm{n}_{\mathrm{Te}}>2\right)$. For example, in the ternary $\mathrm{Si}_{10} \mathrm{Ge}_{10} \mathrm{Te}_{80}$ glass, it was found that $\mathrm{n}_{\mathrm{Si}}=3.87, \mathrm{n}_{\mathrm{Ge}}=3.91$ and $\mathrm{n}_{\mathrm{Te}}=2.39^{31}$. Nevertheless, topological constraint theory is a powerful tool to understand Te-based amorphous chalcogenides.

In the $\mathrm{Si}-\mathrm{Ge}-\mathrm{Te}$ system (Fig. 3a), the maximum value of $<r>$ is 3.7 for $\mathrm{Si}_{22.5} \mathrm{Ge}_{62.5} \mathrm{Te}_{15}$, which is the least stable material in the library. As we approach the GFD, the concentration of Te increases and the network becomes more flexible. The average coordination number decreases toward the optimal value of 2.4 for stable glasses. The sample closest to this magic number, namely $\mathrm{Si}_{14.2} \mathrm{Ge}_{16} \mathrm{Te}_{69.8}$, has an $<r>$ of 2.6 . The $<r>$ values for the entire library are given in Table 1. A map of the flexible and stressed-rigid regions is shown in Fig. $3 \mathrm{~b}$. The average number of constraints increases as we move away from the Te vertex (where $n_{c}=2$ ), towards the tie line between $\mathrm{Si}$ and Ge (where $n_{c}=7$ ). The compositional join line $n_{c}=3$ (tie line between $\mathrm{GeTe}_{4}$ and $\mathrm{SiTe}_{4}$ ) crosses through the middle of the GFD. An important composition for OTS, $\mathrm{GeTe}_{6}$, is near this compositional join line, whereas the stiffness threshold in the $\mathrm{Ge}_{\mathrm{x}} \mathrm{Te}_{100-\mathrm{x}}$ system is found at $x=20$ at $\%$. Also, phase change materials are usually found in the stressed-rigid area of the map, for instance GeTe has $n_{c}=4.5$. All the samples in the library are located in the stressed-rigid region $\left(n_{c}>3\right)$, with $n_{c}$ in the interval 3.5 to 6.2 . 


\begin{tabular}{|c|c|c|c|c|c|c|c|c|c|c|c|}
\hline Composition & $<r>$ & $n_{c}$ & d (nm) & $E_{g}(\mathrm{eV})$ & $E_{0}(\mathrm{eV})$ & $A$ & $\Gamma$ & $\varepsilon_{\infty}$ & $n_{1}$ & $\mathrm{n}_{2}$ & $\mathbf{n}_{3}$ \\
\hline $\mathrm{Si}_{22.5} \mathrm{Ge}_{62.5} \mathrm{Te}_{15}$ & 3.70 & 6.25 & 352.9 & 0.80 & 4.1 & 87.7 & 5.5 & 9.6 & 3.3 & 3.6 & 3.2 \\
\hline $\mathrm{Si}_{36.6} \mathrm{Ge}_{47.9} \mathrm{Te}_{15.5}$ & 3.69 & 6.23 & 353.0 & 0.94 & 4.6 & 73.5 & 6.2 & 7.7 & 3.1 & 3.2 & 2.8 \\
\hline $\mathrm{Si}_{45.6} \mathrm{Ge}_{36.8} \mathrm{Te}_{17.6}$ & 3.65 & 6.12 & 339.5 & 1.02 & 4.5 & 61.5 & 5.6 & 7.6 & 3.0 & 3.0 & 2.7 \\
\hline $\mathrm{Si}_{21.8} \mathrm{Ge}_{53.8} \mathrm{Te}_{24.4}$ & 3.51 & 5.78 & 371.2 & 0.78 & 4.5 & 85.0 & 6.2 & 9.1 & 3.2 & 3.4 & 3.1 \\
\hline $\mathrm{Si}_{30.6} \mathrm{Ge}_{43} \mathrm{Te}_{26.4}$ & 3.47 & 5.68 & 380.8 & 0.87 & 4.8 & 76.5 & 6.8 & 7.8 & 3.0 & 3.2 & 2.9 \\
\hline $\mathrm{Si}_{39.7} \mathrm{Ge}_{33.8} \mathrm{Te}_{26.5}$ & 3.47 & 5.68 & 364.0 & 0.98 & 4.6 & 63.1 & 5.9 & 7.1 & 3.0 & 3.0 & 2.7 \\
\hline $\mathrm{Si}_{15} \mathrm{Ge}_{56.1} \mathrm{Te}_{28.9}$ & 3.42 & 5.55 & 391.3 & 0.71 & 3.7 & 101.1 & 5.1 & 11.8 & 3.4 & 3.9 & 3.6 \\
\hline $\mathrm{Si}_{23.4} \mathrm{Ge}_{46.7} \mathrm{Te}_{29.9}$ & 3.40 & 5.51 & 417.2 & 0.83 & 4.2 & 75.3 & 6.0 & 8.4 & 3.1 & 3.3 & 3.0 \\
\hline $\mathrm{Si}_{32.6} \mathrm{Ge}_{34.8} \mathrm{Te}_{32.6}$ & 3.35 & 5.37 & 407.8 & 0.88 & 4.6 & 67.5 & 6.3 & 7.3 & 2.9 & 3.1 & 2.8 \\
\hline $\mathrm{Si}_{22.2} \mathrm{Ge}_{39.5} \mathrm{Te}_{38.3}$ & 3.23 & 5.09 & 381.5 & 0.86 & 4.2 & 87.0 & 6.2 & 8.9 & 3.2 & 3.4 & 3.1 \\
\hline $\mathrm{Si}_{14.8} \mathrm{Ge}_{45.9} \mathrm{Te}_{39.3}$ & 3.21 & 5.04 & 471.5 & 0.79 & 4.1 & 92.2 & 5.9 & 10 & 3.3 & 3.6 & 3.3 \\
\hline $\mathrm{Si}_{32.4} \mathrm{Ge}_{28.2} \mathrm{Te}_{39.4}$ & 3.21 & 5.03 & 373.9 & 1.02 & 4.3 & 80.5 & 6.8 & 7.5 & 2.9 & 3.1 & 2.8 \\
\hline $\mathrm{Si}_{27.5} \mathrm{Ge}_{32.1} \mathrm{Te}_{40.4}$ & 3.19 & 4.98 & 472.1 & 0.98 & 3.8 & 76.1 & 6.1 & 7.5 & 2.8 & 3.1 & 2.8 \\
\hline $\mathrm{Si}_{20.9} \mathrm{Ge}_{37.6} \mathrm{Te}_{41.5}$ & 3.17 & 4.92 & 494.7 & 0.96 & 3.8 & 91.9 & 6.4 & 8.3 & 3.0 & 3.3 & 3.0 \\
\hline $\mathrm{Si}_{24} \mathrm{Ge}_{33.3} \mathrm{Te}_{42.7}$ & 3.15 & 4.87 & 397.3 & 0.98 & 4.1 & 87.9 & 6.7 & 8.1 & 3.0 & 3.3 & 2.9 \\
\hline $\mathrm{Si}_{12.6} \mathrm{Ge}_{32.4} \mathrm{Te}_{55}$ & 2.90 & 4.25 & 542.4 & 0.89 & 3.5 & 107.4 & 6.1 & 9.9 & 3.1 & 3.6 & 3.3 \\
\hline $\mathrm{Si}_{20.3} \mathrm{Ge}_{23.4} \mathrm{Te}_{56.3}$ & 2.87 & 4.18 & 539.1 & 0.95 & 3.6 & 98.0 & 6.0 & 8.9 & 3.0 & 3.4 & 3.1 \\
\hline $\mathrm{Si}_{8.8} \mathrm{Ge}_{33.1} \mathrm{Te}_{58.1}$ & 2.84 & 4.09 & 326.2 & 0.93 & 2.7 & 83.8 & 4.0 & 9.2 & 2.7 & 3.4 & 3.2 \\
\hline $\mathrm{Si}_{14.9} \mathrm{Ge}_{26.3} \mathrm{Te}_{58.8}$ & 2.82 & 4.06 & 570.5 & 0.92 & 3.3 & 102.0 & 5.6 & 9.5 & 3.0 & 3.5 & 3.2 \\
\hline $\mathrm{Si}_{14.4} \mathrm{Ge}_{24.2} \mathrm{Te}_{61.4}$ & 2.77 & 3.93 & 307.0 & 0.96 & 2.6 & 84.0 & 4.1 & 8.7 & 2.6 & 3.3 & 3.1 \\
\hline $\mathrm{Si}_{17.5} \mathrm{Ge}_{19.7} \mathrm{Te}_{62.8}$ & 2.74 & 3.86 & 299.8 & 0.95 & 2.5 & 72.5 & 3.4 & 8.3 & 2.4 & 3.2 & 3.0 \\
\hline $\mathrm{Si}_{8,1} \mathrm{Ge}_{23.3} \mathrm{Te}_{68.6}$ & 2.63 & 3.57 & 414.7 & 0.94 & 2.5 & 86.9 & 3.3 & 9.6 & 2.6 & 3.6 & 3.2 \\
\hline $\mathrm{Si}_{11.8} \mathrm{Ge}_{19.5} \mathrm{Te}_{68.7}$ & 2.63 & 3.57 & 431.5 & 0.91 & 2.4 & 86.3 & 3.1 & 9.8 & 2.5 & 3.5 & 3.3 \\
\hline $\mathrm{Si}_{14,2} \mathrm{Ge}_{16} \mathrm{Te}_{69.8}$ & 2.60 & 3.51 & 386.0 & 0.88 & 2.4 & 82.3 & 3.2 & 9.7 & 2.5 & 3.5 & 3.3 \\
\hline
\end{tabular}

Table 1. Computed values of $<r>$ and $n_{c}$ from topological constraint theory and spectroscopic ellipsometry modelling parameters for the combinatorial library. The average coordination number, $\langle r\rangle$, and the average number of constraints, $n_{c}$, computed for the prepared compositions. Composition was determined using RBS measurements $(<3$ at $\%)$. From spectroscopic ellipsometry analysis, the thickness $( \pm 0.5 \mathrm{~nm}), E_{g}( \pm 0.01), E_{0}$ $( \pm 0.02), A( \pm 1.0), \Gamma( \pm 0.1), \varepsilon_{\infty}( \pm 0.02)$ and the values of the refractive indices at $405 \mathrm{~nm}\left(\mathrm{n}_{1} \pm 0.03\right), 587.6 \mathrm{~nm}$ $\left(\mathrm{n}_{2} \pm 0.03\right)$ and $1550 \mathrm{~nm}\left(\mathrm{n}_{3} \pm 0.03\right)$ are tabulated (the given errors are the highest resulted from the fitting procedure).

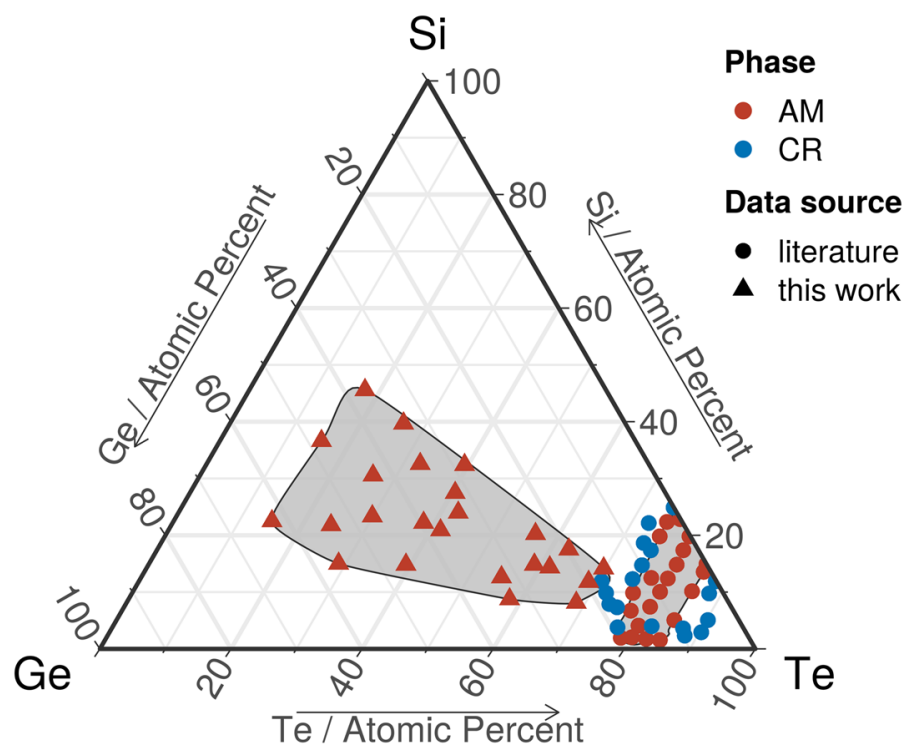

Figure 2. Si-Ge-Te ternary diagram. The structure of the as-deposited $\mathrm{Si}-\mathrm{Ge}-\mathrm{Te}$ library and the GFD from Ref. $^{28}$. Amorphous (AM) compositions are shown in red color and crystalline (CR) samples are depicted in blue. Generated with the R software [v. 3.6.3] (R: A language and environment for statistical computing, R Core Team, R Foundation for Statistical Computing, Vienna, Austria (2020) http://www.R-project.org/.) using the package ggtern [v. 3.3.0] (https://cran.r-project.org/web/packages/ggtern/index.html). 

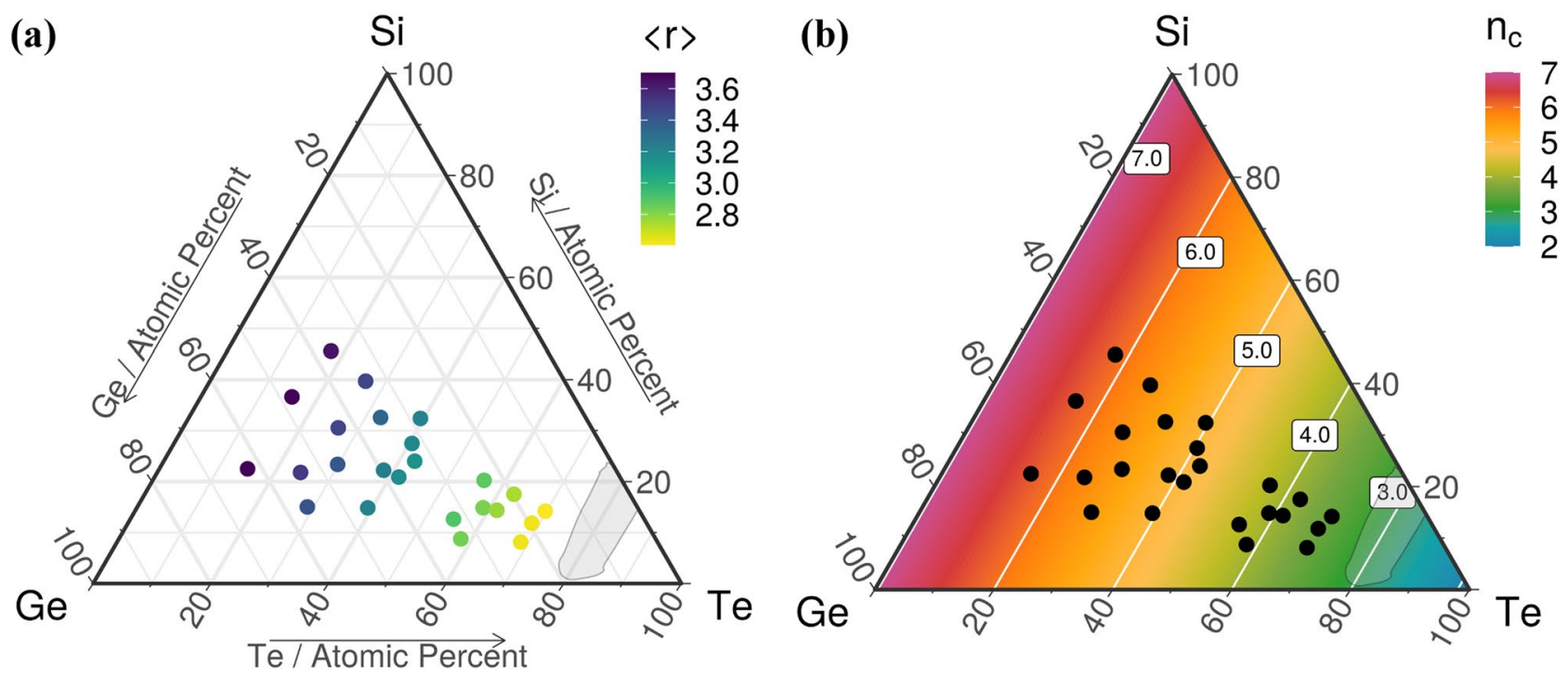

Figure 3. Topological constraint theory parameters for the Si-Ge-Te system. (a) The average coordination number and (b) the average number of constraints. In gray is depicted the glass formation domain. Ternary diagrams were generated with the $\mathrm{R}$ software [v. 3.6.3] (R: A language and environment for statistical computing, R Core Team, R Foundation for Statistical Computing, Vienna, Austria (2020) http://www.R-proje ct.org/.) using the packages ggtern [v. 3.3.0] (https://cran.r-project.org/web/packages/ggtern/index.html) and directlabels [v. 2020.6.17] (https://cran.r-project.org/web/packages/directlabels/index.html).

Optical properties. Due to their applications in optical data storage $e^{38}$ and optical sensors ${ }^{39}$, the optical properties of amorphous chalcogenide materials are of great interest for the digital era. Spectroscopic ellipsometry is a sensitive technique used to measure the thickness and optical constants of amorphous and crystalline chalcogenide materials ${ }^{40,41}$.

The extracted values of the parameters used to model the experimental data are shown in Figs. 4, 5 and in Table 1. All the fitted ellipsometry data are shown in Supplementary Figure S2. The mean squared errors (MSE) values we have obtained in the present study are between 6 and 68. It seems that MSE increases as the Si quantity increases.

$E_{g}$ in $\mathrm{Si}-\mathrm{Ge}-\mathrm{Te}$ is determined by the concentration of both cation and anion species. Most of the amorphous telluride materials in the library have an $E_{g}$ around $0.95 \mathrm{eV}$, as can be seen in Fig. $4 \mathrm{a}$. Jovari et al. ${ }^{11}$ showed that in thermally co-evaporated amorphous $\mathrm{Ge}_{\mathrm{x}} \mathrm{Te}_{100-\mathrm{x}}$ alloys $(12 \leq \mathrm{x} \leq 44.6)$ the majority of atoms obey the $8-N$ rule, but there are homopolar bonds which evolve monotonically with increasing $\mathrm{x}$ (the percent of Te-Te bonds decreases from 73.4 to $35.9 \%$, while the percent of $\mathrm{Ge}-\mathrm{Ge}$ bonds increases from 1 to $56.6 \%$ ), resulting in chemical disorder. This suggests that the $\mathrm{Te}, \mathrm{Si}$ and Ge nano-clusters can make an important contribution to the optical band gap of amorphous $\mathrm{Si}-\mathrm{Ge}-\mathrm{Te}$ compositions.

According to $\mathrm{K}$. Tanaka ${ }^{12}$, the width of the conduction band is proportional with the average coordination number $\langle r\rangle$, while the width of the valence band is inversely proportional to the length of van der Waals bonds in chalcogenide glasses. Considering that the difference between the centers of the conduction and valence bands is constant (simple tight binding electrons model), the dependence of $E_{g}$ on $\langle r\rangle$ shows a minimum at $\langle r\rangle=2.4$ due to an increase of the conduction band width which produces a decrease in $E_{g}$. Then $E_{g}$ increases, when $<r>$ is between 2.4 and 2.67, due to the increase in the van der Waals bonds which produces a decrease in the width of the valence band and therefore the increase in $E_{g}$. A similar behaviour was observed in covalent chalcogenide glasses ${ }^{42}$. The small shifts from these values, observed in the Si-Ge-Te system, Fig. 4c, are produced by the ionic and metallic character of telluride materials. The variation of the bandgap with the average coordination number in Fig. $4 c$, shows traces of a minimum at small $\langle r\rangle$. A peak in the bandgap is observed for $\langle r\rangle \sim 2.75$, which echoes the maximum at 2.67 observed in other chalcogenide glasses ${ }^{43,44}$. The value of 2.67 is related to planar network glasses, where the angular constraints $\left(n_{B B}\right)$ are reduced from $2<r>-3$ to $<r>-1$, resulting in an average coordination number of 2.67 when $n_{c}=3$. After this peak, the bandgap decreases again due to the increase in the width of the conduction band. Above 3, there is no clear dependence of $E_{g}$ on $\langle r\rangle$.

Figure $4 \mathrm{~d}$ shows the variation of the bandgap with the $\mathrm{Ge}$ concentration. We can observe that the bandgap has a maximum between 23 and 36 at\% Ge. A similar dependence was observed by C. Vigreux et al. ${ }^{45}$ in Ge-Te films. These singularities in bandgap can also be linked to nanophase separation as suggested by Boolchand et al. ${ }^{46}$.

The critical energy, $E_{0}$, shown in Fig. $5 \mathrm{a}$, has a minimum value of $2.4 \mathrm{eV}$ for $\mathrm{Si}_{11.8} \mathrm{Ge}_{19.5} \mathrm{Te}_{68.7}$ and $\mathrm{Si}_{14.2} \mathrm{Ge}_{16} \mathrm{Te}_{69.8}$, and a maximum of $4.8 \mathrm{eV}$ for $\mathrm{Si}_{30.6} \mathrm{Ge}_{43} \mathrm{Te}_{26.4}$. For energies above the bandgap, electronic critical point transitions in the dielectric function are present due to electron transitions between the valence and conduction bands ${ }^{47}$. In chalcogenides, the upper edge of the valence band is composed of lone pair states ${ }^{48}$, so above the bandgap there are transitions from these states to the conduction band. $E_{0}$ is linearly dependent on the Te concentration. As the Te concentration increases, the resonance energy decreases (Fig. 5b). 


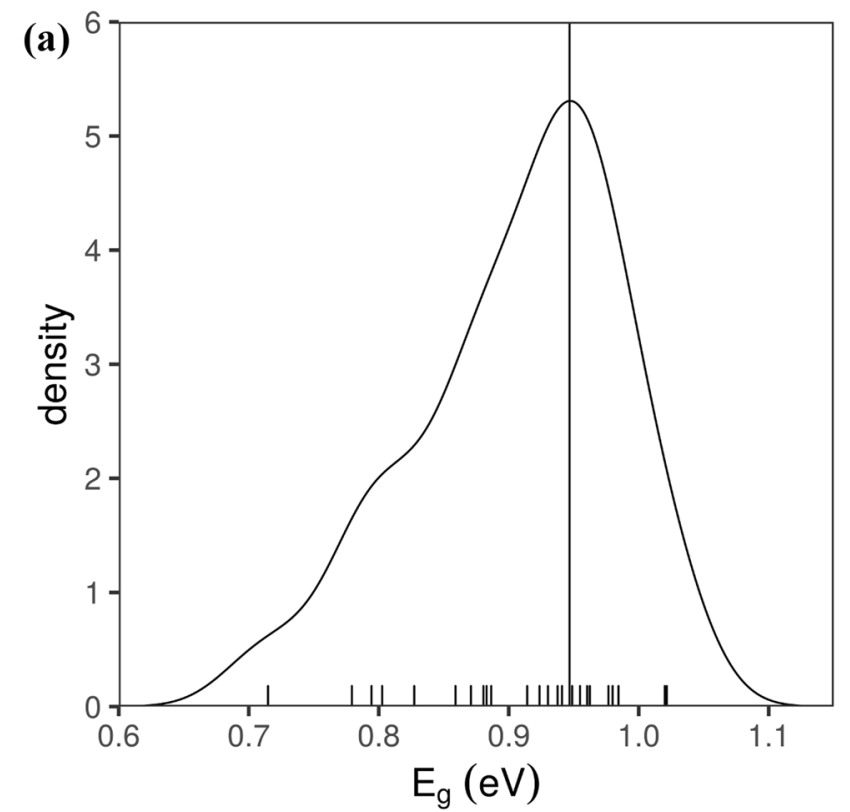

(b)
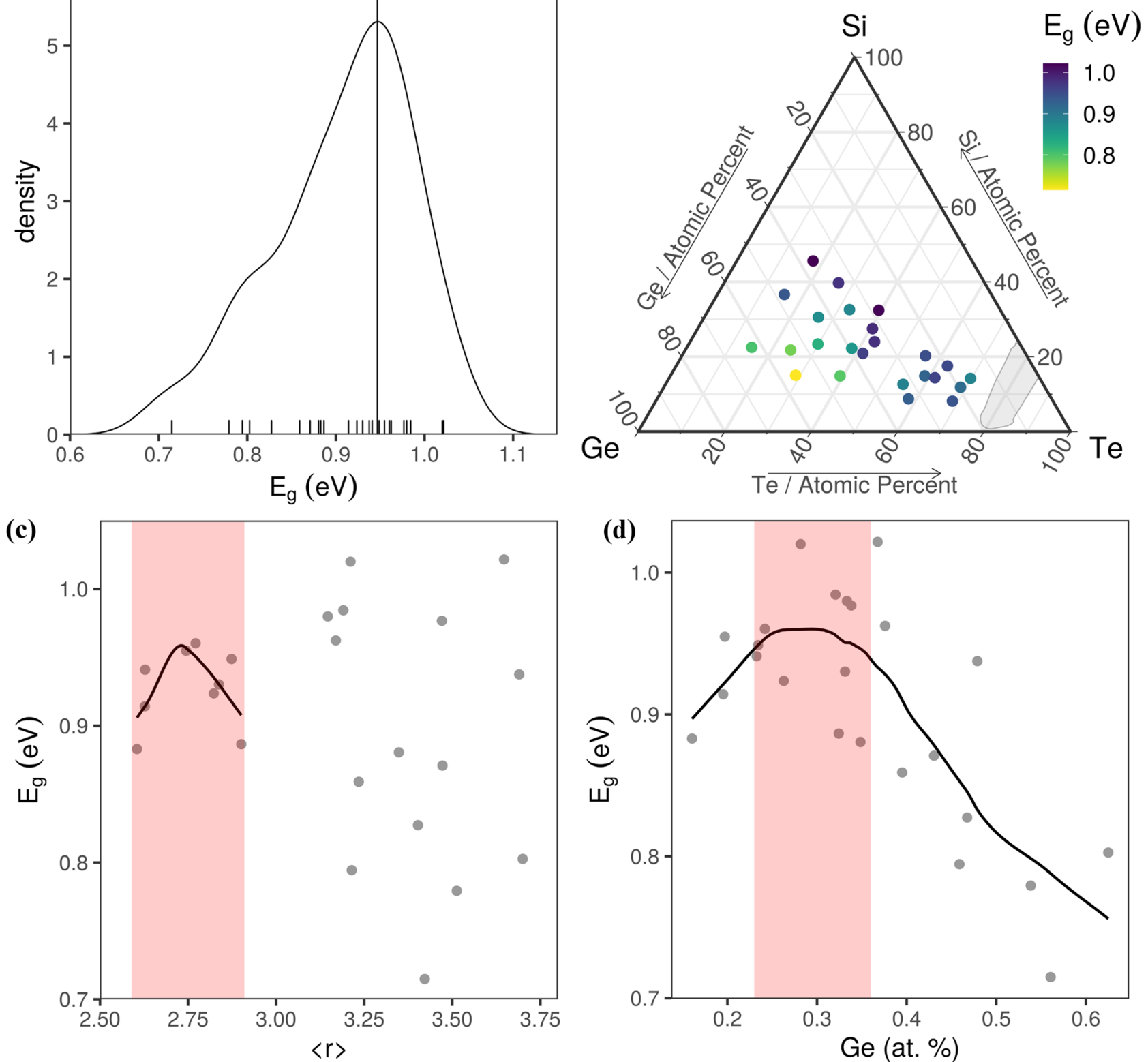

Figure 4. Variation of bandgap in the Si-Ge-Te system. (a) The probability density function of $E_{g}$; Bandgap as a function of: (b) composition, (c) the average coordination number, (d) Ge concentration. The black lines and red shaded areas in (c) and (d) are guides to the eye. The ternary diagram in (b) was generated with the $\mathrm{R}$ software [v. 3.6.3] (R: A language and environment for statistical computing, R Core Team, R Foundation for Statistical Computing, Vienna, Austria (2020) http://www.R-project.org/.) using the package ggtern [v. 3.3.0] (https://cran.r-project.org/web/packages/ggtern/index.html).

The broadening parameter is scaling inversely with the lifetime of carriers excited into deep states in the conduction and valence bands ${ }^{49}$. If the broadening is small, it indicates a more ordered material with less scattering. Strain and defects in crystalline networks, lead to a higher broadening and lower mean free path of carriers. In amorphous networks there are similar defects in the continuous random network. In the $\mathrm{Si}-\mathrm{Ge}-\mathrm{Te}$ system, as the compositions approach the GFD, the average coordination number decreases and the structural order increases (bond lengths and bond angles distributions are narrower), which is observed by the decrease of $\Gamma$ (Fig. $5 \mathrm{c}$ ). The most ordered composition is $\mathrm{Si}_{11.8} \mathrm{Ge}_{19.5} \mathrm{Te}_{68.7}$ with $\Gamma=3.1$, while the least ordered are $\mathrm{Si}_{30.6} \mathrm{Ge}_{43} \mathrm{Te}_{26.4}$ and $\mathrm{Si}_{32.4} \mathrm{Ge}_{28.2} \mathrm{Te}_{39.4}$ with $\Gamma=6.8$. An abrupt transition, from disorder $(\Gamma \sim 6)$ to order $(\Gamma \sim 4)$, is observed when the Te concentration reaches 60 at $\%$, while above this value the decrease is linear (Fig. $5 \mathrm{~d}$ ). The values obtained for $\Gamma$ are comparable to those of other amorphous chalcogenide materials ${ }^{40,41,50}$. The abrupt drop in the broadening parameter usually accompanies structural changes and was observed for Te-based chalcogenides such as $\mathrm{Ge}-\mathrm{Te}{ }^{41}$ and $\mathrm{Ge}-\mathrm{Sb}-\mathrm{Te}^{51}$. Moreover, a systematic decrease of $\Gamma$ with increasing chalcogenide content in glasses was also 
(a)

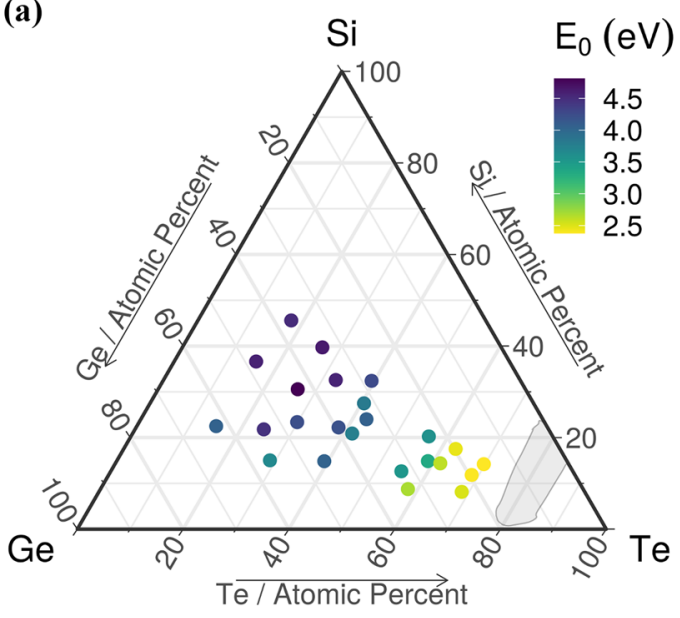

(c)

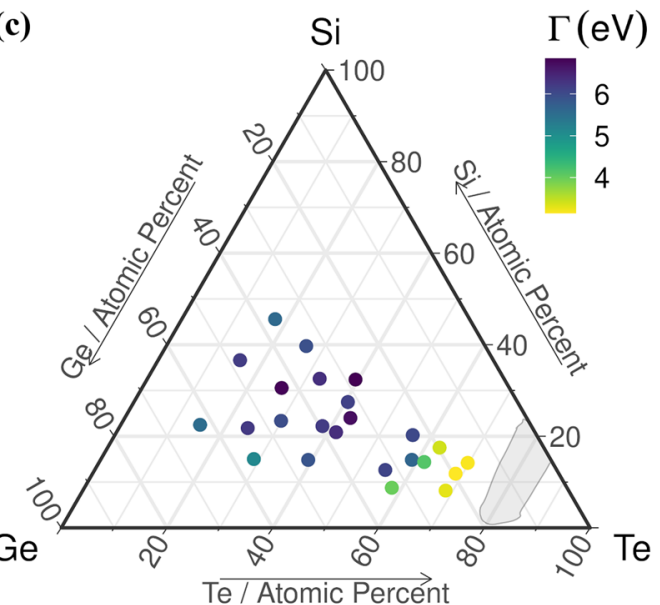

(e)

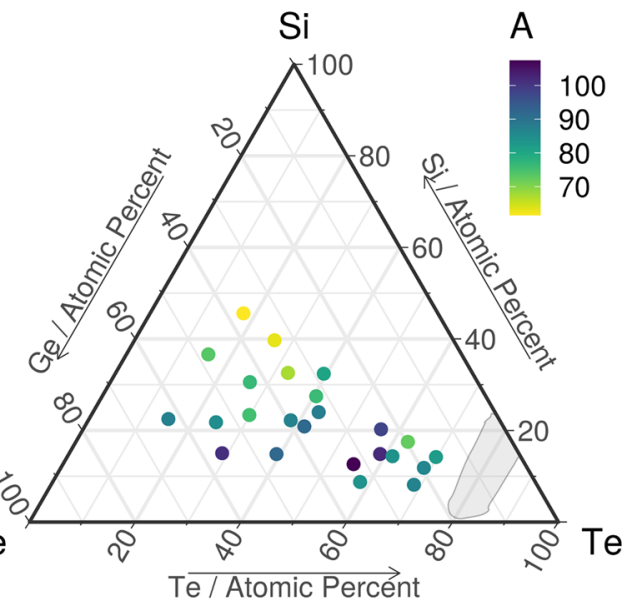

(b)
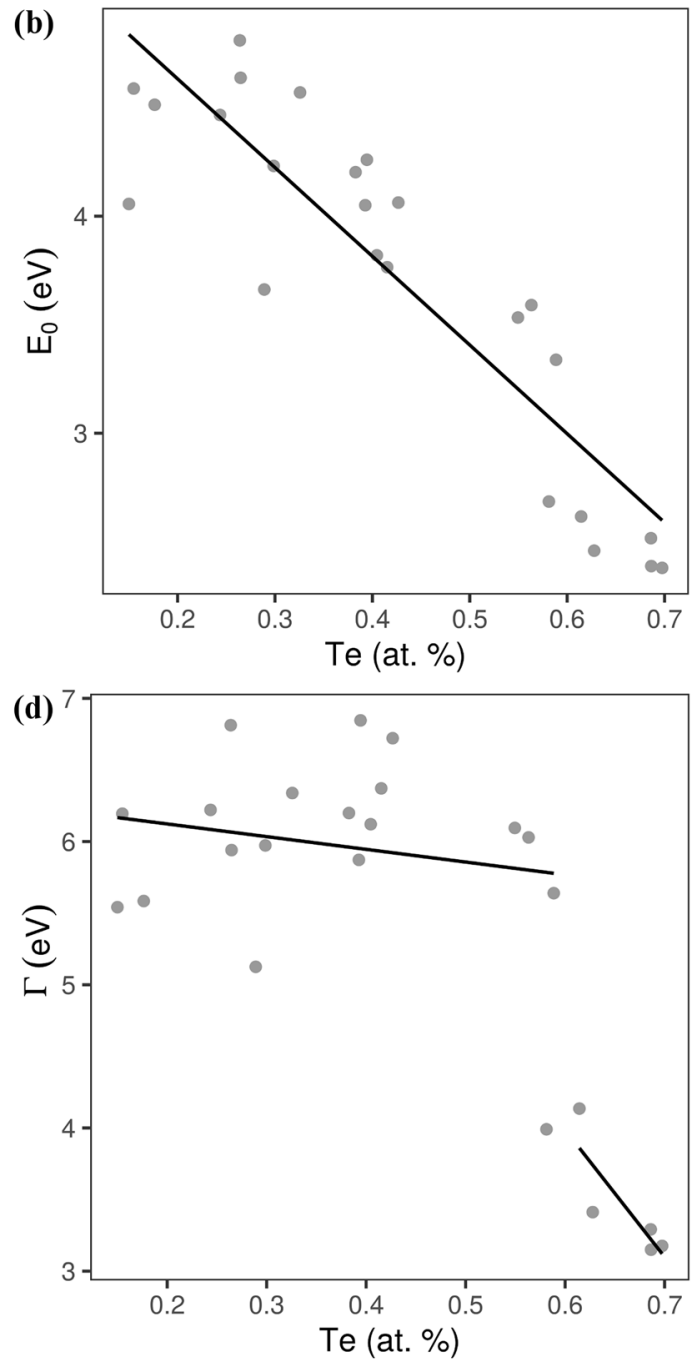

(f)

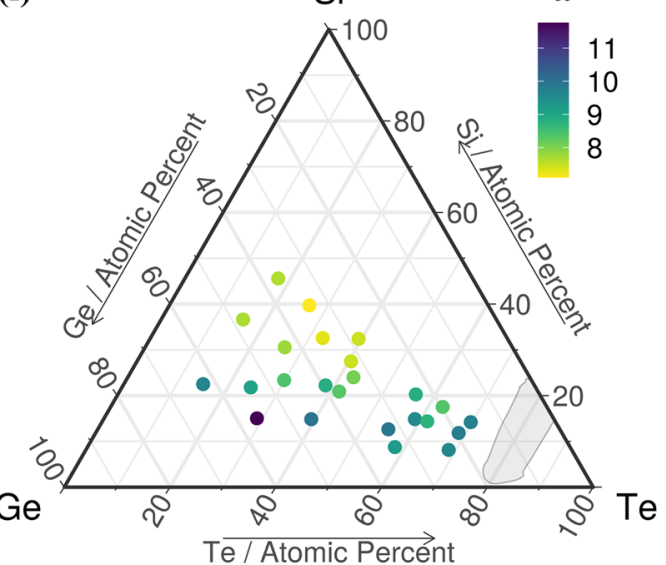

Figure 5. Spectroscopic ellipsometry parameters for the $\mathrm{Si}-\mathrm{Ge}-\mathrm{Te}$ library. Resonance energy, $E_{0}$, as a function of (a) composition and (b) Te concentration; Broadening parameter of the oscillator, $\Gamma$, as a function of (c) composition and (d) Te concentration; (e) Amplitude, A, as a function of composition; and (f) Optical dielectric constant, $\varepsilon_{\infty}$, as a function of composition. The black line in $(\mathbf{b})$ and $(\mathbf{d})$ is a guide to the eye. Ternary diagrams were generated with the R software [v. 3.6.3] (R: A language and environment for statistical computing, R Core Team, R Foundation for Statistical Computing, Vienna, Austria (2020) http://www.R-project.org/.) using the package ggtern [v. 3.3.0] (https://cran.r-project.org/web/packages/ggtern/index.html). 

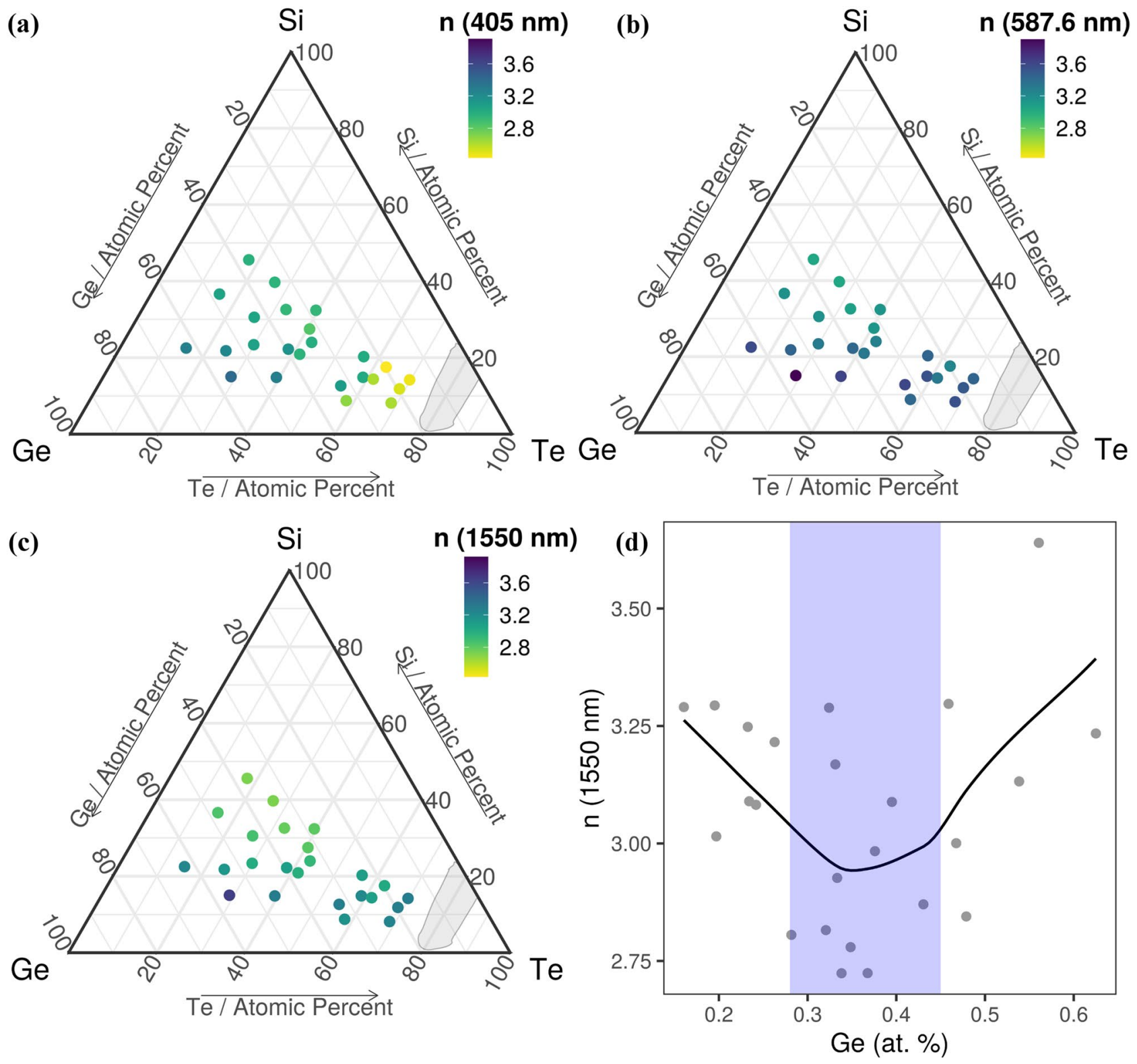

Figure 6. The refractive index at different wavelengths: (a) $405 \mathrm{~nm}$; (b) $587.6 \mathrm{~nm}$; (c) $1550 \mathrm{~nm}$ and (d) The variation of the near-IR refractive index as a function of $\mathrm{Ge}$ concentration. The black line and blue shaded area in (d) are guides to the eye. Ternary diagrams were generated with the R software [v. 3.6.3] (R: A language and environment for statistical computing, R Core Team, R Foundation for Statistical Computing, Vienna, Austria (2020) http://www.R-project.org/.) using the package ggtern [v. 3.3.0] (https://cran.r-project.org/web/packages/ ggtern/index.html).

observed by Orava et $\mathrm{al}^{52}$. The amplitude, A, Fig. 5 e, has the minimum value of 61.5 for $\mathrm{Si}_{45.6} \mathrm{Ge}_{36.8} \mathrm{Te}_{17.6}$, the sample with the highest concentration of $\mathrm{Si}$, and the maximum value of 107.4 for $\mathrm{Si}_{12.6} \mathrm{Ge}_{32.4} \mathrm{Te}_{55}$.

$\varepsilon_{\infty}$, which is linked to the degree of polarization, is shown in Fig. 5 f. Below the bandgap, the dielectric function is governed by the electronic polarizability of the valence electrons ${ }^{53}$. $\varepsilon_{\infty}$ for Te is 11 for the amorphous phase $e^{54}$, which is in accordance with the values obtained by us. It increases with the increase of Te concentration and the decrease of Si.

In the visible domain, chalcogenide glasses are generally characterized by the value of their refractive index, $n$, near the center of the domain ( $587.6 \mathrm{~nm}$ at the $d$ spectral line of $\mathrm{He}$ ). Chalcogenide amorphous thin films are important in the production of near-IR $(1550 \mathrm{~nm})$ integrated optical devices for the detection of biological or environmental variations ${ }^{39}$ and Blu-ray discs (BD) ${ }^{1}$. The refractive indices at $405 \mathrm{~nm}$ (the wavelength used for $\mathrm{BD}$ ), at $587.6 \mathrm{~nm}$ (visible region) and $1550 \mathrm{~nm}$ (near-IR region) are shown in Fig. 6 and Table 1. The extinction coefficient for the same wavelengths is shown in Fig. S3. The Te percent has a large influence on the refractive index, which increases when the Te concentration increases. For low wavelengths ( $405 \mathrm{~nm}$, Fig. 6a), the refractive index has a minimum close to the GFD (the composition with the lowest refractive index is $\mathrm{Si}_{17.5} \mathrm{Ge}_{19.7} \mathrm{Te}_{62.8}$ with 
$\mathrm{n}=2.4$ ), whereas for higher wavelengths $(587.6 \mathrm{~nm}$ and $1550 \mathrm{~nm}$, Fig. $6 \mathrm{~b}, \mathrm{c})$ the trend reverses and the refractive index increases near GFD.

The refractive index at $1550 \mathrm{~nm}$ has a minimum in the region between 28 and 45 at\% of Ge (Fig. $6 \mathrm{~d}$ ). Such a minimum is very important in near-IR waveguides applications, because it shows that the refractive index can be controlled by the Ge concentration. The optical properties of the combinatorial Si-Ge-Te library, such as the bandgap and the refractive index, can be gradually modified with composition and show important extrema in their dependence.

Thermal stability. The glass transition temperature, $T_{g}$, is defined as the transition temperature from a glassy state to a supercooled liquid, viscous state ${ }^{12}$. At high temperatures (higher than the melting temperature), the liquid has the configuration with the highest enthalpy, whereas at room temperature, the crystal has the smallest enthalpy. Instead, at room temperature, the glass has a local minimum enthalpy, that corresponds to a quasi-equilibrium or metastable state. So, the glass transition is a kinetic phenomenon where structural relaxation occurs. Structural relaxation consists of atomic rearrangements that allow the material to reach the equilibrium state at a given temperature.

Te-based materials should crystallize above the glass transition temperature ${ }^{55}$, therefore the glass transition temperature can be considered the lower limit for crystallization ${ }^{2}$. Two models are used to estimate $T_{g}$. First, using the Lankhorst model, the computed $T_{g}$ values, are in the interval $142.1{ }^{\circ} \mathrm{C}$ (for $\left.\mathrm{Si}_{8.1} \mathrm{Ge}_{23.3} \mathrm{Te}_{68.6}\right) \div 553.5^{\circ} \mathrm{C}$ (for $\mathrm{Si}_{45.6} \mathrm{Ge}_{36.8} \mathrm{Te}_{17.6}$ ) for compositions with the lowest and highest amount of $\mathrm{Si}$, respectively, and are shown in Fig. $7 \mathrm{a}$, and Table 2. Second, the obtained $T_{g}$ values, from the Stochastic agglomeration model, are between $181.4^{\circ} \mathrm{C}$ (for $\mathrm{Si}_{14.2} \mathrm{Ge}_{16} \mathrm{Te}_{69.8}$ ) $\div 328.7^{\circ} \mathrm{C}$ (for $\mathrm{Si}_{22.5} \mathrm{Ge}_{62.5} \mathrm{Te}_{15}$ ) for the compositions with the highest and lowest amount of Te, respectively, and are presented in Fig. $7 \mathrm{~b}$ and Table 2.

In Fig. 7c, the predictions of the two models, namely the Lankhorst ${ }^{56}$ model and the stochastic agglomeration model $^{57,58}$, used to estimate $T_{g}$, are compared. As a general observation, both models predict that $T_{g}$ decreases with the increase of Te concentration. It is known that $T_{g}$ rises with the increase of silicon content in $\mathrm{Si}-\mathrm{Te}$ glasses, and by substituting germanium for silicon, the $T_{g}$ values first increase and then decrease ${ }^{28}$. The Lankhorst model underestimates ${ }^{55} T_{g}$, as we also observe in Fig. $7 \mathrm{c}$ for high Te concentrations. Both models predict a similar transition temperature for $\mathrm{Si}_{14.4} \mathrm{Ge}_{24.2} \mathrm{Te}_{61.4 .}\left(T_{g}{ }^{L}=204.9^{\circ} \mathrm{C}\right.$ and $\left.T_{g} S=203.8^{\circ} \mathrm{C}\right)$. Also, for the three compositions on the tie line between $\mathrm{Ge}_{2} \mathrm{Te}_{3}$ and $\mathrm{Si}_{2} \mathrm{Te}_{3}\left(\mathrm{Si}_{8.8} \mathrm{Ge}_{33.1} \mathrm{Te}_{58.1}, \mathrm{Si}_{14.9} \mathrm{Ge}_{26.3} \mathrm{Te}_{58.8}\right.$ and $\left.\mathrm{Si}_{17.5} \mathrm{Ge}_{19.7} \mathrm{Te}_{62.8}\right)$ the predictions of the two models are very close (difference $<15^{\circ} \mathrm{C}$ ). At low Te concentrations (below 35 at\%), Lankhorst's model predicts that 9 of the samples should have a $T_{g}$ higher than $400{ }^{\circ} \mathrm{C}$ (the first nine compositions in Table 2).

In order to test the thermal stability of the amorphous films and to see which model gives more accurate $T_{g}$ estimates, the samples were annealed at $400^{\circ} \mathrm{C}$. Moreover, for some applications, such as OTS ${ }^{2}$, the amorphous phase should meet the processing needs of back-end-of-line (BEOL) integration, so this test should also show which compositions in the library satisfy this requirement. Since the glass transition temperature can be considered the lower limit for crystallization ${ }^{2}$, if the compositions stay amorphous up to $400^{\circ} \mathrm{C}$, then the Lankhorst model predicts well $T_{g}$, otherwise if the samples crystallize below this temperature, then the stochastic agglomeration model is more precise. The results are shown in Fig. 8a, where it can be observed that all samples are crystalline at $400{ }^{\circ} \mathrm{C}$. In conclusion, the stochastic agglomeration model is more accurate in predicting the glass transition temperatures.

Based on the crystalline phases which are formed, several groups can be distinguished in the Si-Ge-Te ternary diagram (Fig. 8a). The GIXRD patterns of all our samples before and after annealing are shown in Supplementary Fig. S1.

The first group (blue dots in Fig. 8a) contains the samples with the lowest concentration of Te (less than 40 at $\%$, see also Fig. 8d). These samples crystallize in the rhombohedral germanium telluride phases (space group R3m (160) or R-3 m (166), PDF \# 04-002-6696, PDF \# 04-002-5568, PDF \# 04-002-5568 or PDF \# 00-047-1079). These are GeTe phases or GeTe phases with a small Te excess (see Table 2). The remaining Ge and Si form, most probable, a minority $\mathrm{Ge}_{\mathrm{x}} \mathrm{Si}_{1-\mathrm{x}}$ amorphous phase.

The second group (green dots in Fig. 8a) contains two samples which crystallize in majority in rhombohedral GeTe (space group R3m (160) or R-3 m (166), PDF 01-076-7106 and PDF \# 00-047-1079) and in minority in hexagonal Te (space group P3121 (152), PDF \# 00-036-1452). These are samples with a lower concentration of $\mathrm{Si}$ (less than 15 at\%, see also Fig. 8c) than the first group. Small quantities of amorphous $\mathrm{Ge}_{\mathrm{x}} \mathrm{Si}_{1-\mathrm{x}}$ are also present in these samples.

The third group (orange dots in Fig. 8a) is composed of hexagonal Te (space group P3121 (152), PDF 00-0361452 ) in majority and rhombohedral GeTe in minority (space group R3m (160) or R-3 m (166), PDF \# 04-0025568, PDF \# 04-002-5662 or PDF \# 00-047-1079).

The last group, which is also the largest one, is formed of hexagonal Te (space group P3121 (152), PDF 00-036-1452). There is no clear delimitation between the third and the fourth group, however above 60 at $\%$ of Te (Fig. 8d) only crystalline Te is found in the samples. In Fig. 8b,d, one can observe that the Ge and Te concentrations are positively correlated with the different crystalline phases. As we increase the Ge concentration, the crystalline phases formed are dominated by Ge-based phases and the reverse is true for Te. On the other hand, Te-rich compounds easily crystallize due to the isotropic atomic bonds ${ }^{12}$.

$\mathrm{Si}-\mathrm{Te}$ phases have higher crystallization temperatures than $\mathrm{Ge}-\mathrm{Te}$, this is why $\mathrm{Si}$-Te crystalline phases are never obtained in our samples (Fig. 8c). As shown by Koo et al. ${ }^{59}$, the SiTe composition crystallizes above $400{ }^{\circ} \mathrm{C}$. Other crystalline $\mathrm{Si}$-Te phases with a lower crystallization temperature are $\mathrm{Si}_{2} \mathrm{Te}_{3}$ and $\mathrm{SiTe}_{4} \cdot \mathrm{Si}_{2} \mathrm{Te}_{3}$ crystalizes between 290 and $320^{\circ} \mathrm{C}^{2,60}$, while $\mathrm{SiTe}_{4}$ at $236^{\circ} \mathrm{C}^{61}$. There is more $\mathrm{Ge}$ than $\mathrm{Si}$ in the compositional library, except for only one sample with the highest amount of $\mathrm{Si} 45.6$ at \%, but a low amount of Te, 17.6 at $\%$, which prohibits the formation of $\mathrm{Si}_{2} \mathrm{Te}_{3}$ or $\mathrm{SiTe}_{4}$. Tellurium starts to crystallize slightly above $100^{\circ} \mathrm{C}^{2}$ while $\mathrm{GeTe}$ at $138^{\circ} \mathrm{C}^{12}$. So, Te is always already 
(a)

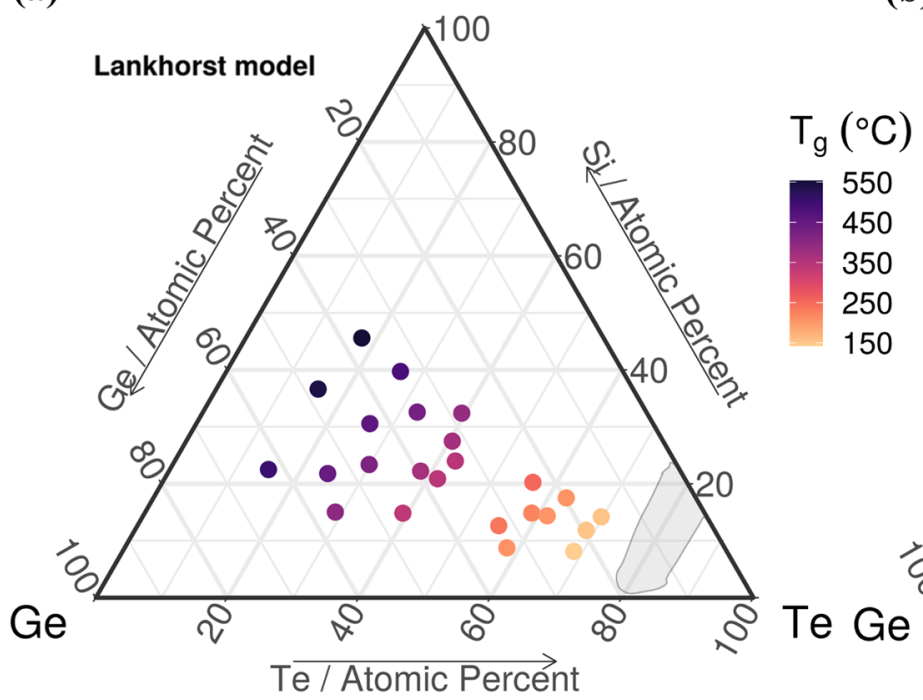

(b)

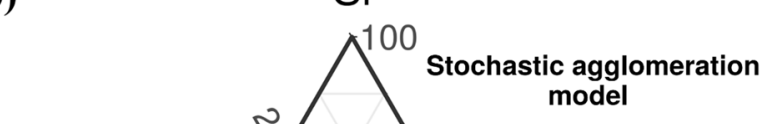

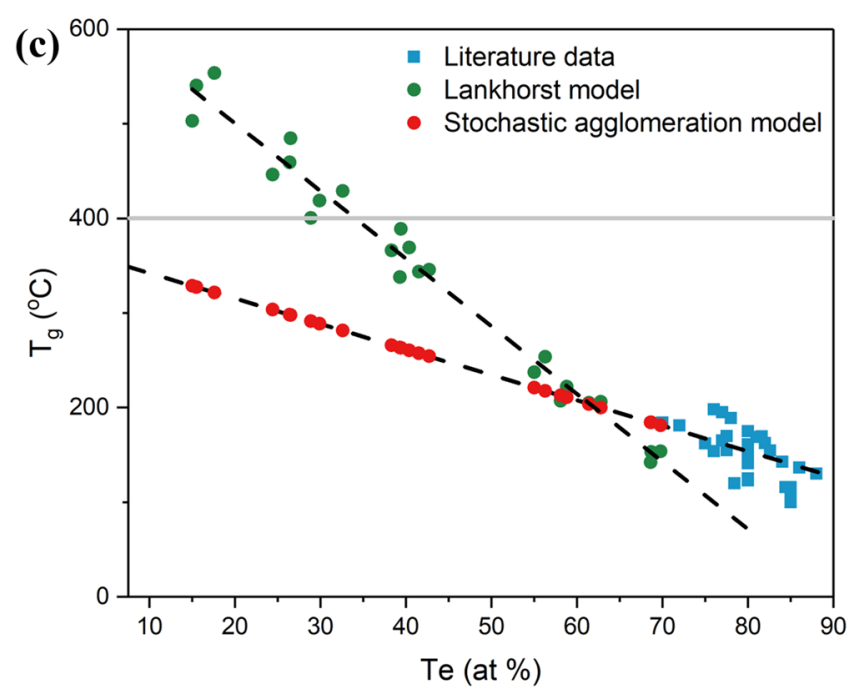

Figure 7. Glass transition temperature of the Si-Ge-Te library. Ternary diagrams showing (a) $T_{g}$ computed with the Lankhorst mode ${ }^{56}$ and (b) the stochastic agglomeration model ${ }^{57,58}$, for the sputtered library. (c) $T_{g}$ as a function of Te concentration, for arbitrary Si and Ge concentration. Computed values for Lankhorst model (a) are shown as green dots, and as red dots for the Stochastic agglomeration model (b). The blue squares show experimental data from literature ${ }^{28,31}$. The black dashed lines are guides to the eye. Ternary diagrams were generated with the R software [v. 3.6.3] (R: A language and environment for statistical computing, R Core Team, R Foundation for Statistical Computing, Vienna, Austria (2020) http://www.R-project.org/.) using the package ggtern [v. 3.3.0] (https://cran.r-project.org/web/packages/ggtern/index.html).

consumed in other crystalline phases when the crystallization temperature of $\mathrm{Si}-\mathrm{Te}$ phases is reached. Usually, in as deposited samples, $\mathrm{Si}$ spreads as a-Si or a- $\mathrm{Ge}_{\mathrm{X}} \mathrm{Si}_{1-\mathrm{x}}$ and delays the crystallization of $\mathrm{Te}$ or $\mathrm{GeTe}^{2}$ rather than forming $\mathrm{Si}-\mathrm{Te}$ crystalline phases when $\mathrm{Ge}$ is also present in the material. Amorphous compositions above $400{ }^{\circ} \mathrm{C}$, reported in a previous study ${ }^{2}$, had a Si concentration greater than 50 at $\%$, which is not the case in our library.

\section{Conclusions}

A Si-Ge-Te combinatorial thin films library was prepared using magnetron co-sputtering. The compositional, structural and optical properties were explored. The RBS measurements showed that an uninvestigated until now domain in the compositional space, was obtained: Si $[7.7 \div 45.6]$ at $\%$, Ge $[11.2 \div 62.5]$ at\%, Te $[15 \div 69.8]$ at $\%$. In the as-deposited state all the samples have amorphous structure and the order of the amorphous networks increases towards the GFD. The Tauc-Lorentz model used to fit the spectroscopic ellipsometry data allows for the determination of the thickness, bandgap, critical energies, optical dielectric constants and refractive indices in visible and near-IR. These properties are discussed in relation to the GFD of bulk glasses, the average coordination number and number of constraints. The bandgap varies between $0.71 \mathrm{eV}$ and $1.02 \mathrm{eV}$ and shows traces of a maximum at $\langle r\rangle \sim 2.75$. The near-IR refractive index varies from 2.7 to 3.6 , and has a minimum when the Ge concentration is between 28 and 45 at\%. A threshold in the broadening parameter of the Lorentz oscillator is 


\begin{tabular}{|c|c|c|c|}
\hline Composition & Crystalline phase & $T_{g}^{L}\left({ }^{\circ} \mathrm{C}\right)$ & $T_{g}^{S}\left({ }^{\circ} \mathrm{C}\right)$ \\
\hline $\mathrm{Si}_{22.5} \mathrm{Ge}_{62.5} \mathrm{Te}_{15}$ & Rhombohedral $\mathrm{Ge}_{0.99} \mathrm{Te}_{1.01}$, PDF 04-002-6696, s.g. R3m (160) & 503.0 & 328.7 \\
\hline $\mathrm{Si}_{36.6} \mathrm{Ge}_{47.9} \mathrm{Te}_{15.5}$ & Rhombohedral $\mathrm{Ge}_{0.99} \mathrm{Te}_{1.01}$, PDF 04-002-6696, s.g. R3m (160) & 540.1 & 327.4 \\
\hline $\mathrm{Si}_{45.6} \mathrm{Ge}_{36.8} \mathrm{Te}_{17.6}$ & Rhombohedral $\mathrm{Ge}_{0.99} \mathrm{Te}_{1.01}$, PDF 04-002-6696, s.g. R3m (160) & 553.5 & 321.6 \\
\hline $\mathrm{Si}_{21.8} \mathrm{Ge}_{53.8} \mathrm{Te}_{24.4}$ & Rhombohedral $\mathrm{Ge}_{0.99} \mathrm{Te}_{1.01}$, PDF 04-002-6696, s.g. R3m (160) & 446.1 & 303.5 \\
\hline $\mathrm{Si}_{30.6} \mathrm{Ge}_{43} \mathrm{Te}_{26.4}$ & $\begin{array}{l}\text { Hexagonal Te, PDF 03-065-2270, s.g. P3121 (152) } \\
\text { Rhombohedral Ge }{ }_{0.978} \mathrm{Te} \text {, PDF 04-002-5662, s.g. R3m (160) }\end{array}$ & 459.2 & 298.1 \\
\hline $\mathrm{Si}_{39.7} \mathrm{Ge}_{33.8} \mathrm{Te}_{26.5}$ & $\begin{array}{l}\text { Hexagonal Te, PDF 03-065-2270, s.g. P3121 (152) } \\
\text { Rhombohedral Ge0.976Te, PDF 04-002-5568, s.g. R3m (160) }\end{array}$ & 484.8 & 297.8 \\
\hline $\mathrm{Si}_{15} \mathrm{Ge}_{56.1} \mathrm{Te}_{28.9}$ & $\begin{array}{l}\text { Rhombohedral GeTe, PDF 00-047-1079, s.g. R3m (166) } \\
\text { Hexagonal Te, PDF 00-036-1452, s.g. P3121 (152) }\end{array}$ & 400.5 & 291.3 \\
\hline $\mathrm{Si}_{23.4} \mathrm{Ge}_{46.7} \mathrm{Te}_{29.9}$ & Rhombohedral GeTe, PDF 00-047-1079, s.g. R3m (166) & 418.6 & 288.7 \\
\hline $\mathrm{Si}_{32.6} \mathrm{Ge}_{34.8} \mathrm{Te}_{32.6}$ & Rhombohedral GeTe, PDF 00-047-1079, s.g. R3m (166) & 429.0 & 281.4 \\
\hline $\mathrm{Si}_{22.2} \mathrm{Ge}_{39.5} \mathrm{Te}_{38.3}$ & Hexagonal Te, PDF 03-065-2270, s.g. P3121 (152) & 366.2 & 266.1 \\
\hline $\mathrm{Si}_{14.8} \mathrm{Ge}_{45.9} \mathrm{Te}_{39.3}$ & Rhombohedral GeTe, PDF 00-047-1079, s.g. R3m (166) & 338.0 & 263.4 \\
\hline $\mathrm{Si}_{32.4} \mathrm{Ge}_{28.2} \mathrm{Te}_{39.4}$ & Hexagonal Te, PDF 03-065-2270, s.g. P3121 (152) & 388.7 & 263.0 \\
\hline $\mathrm{Si}_{27.5} \mathrm{Ge}_{32.1} \mathrm{Te}_{40.4}$ & Hexagonal Te, PDF 00-036-1452, s.g. P3121 (152) & 369.0 & 260.2 \\
\hline $\mathrm{Si}_{20.9} \mathrm{Ge}_{37.6} \mathrm{Te}_{41.5}$ & $\begin{array}{l}\text { Hexagonal Te, PDF 00-036-1452, s.g. P3121 (152) } \\
\text { Rhombohedral GeTe, PDF 00-047-1079, s.g. R3m (166) }\end{array}$ & 343.8 & 257.4 \\
\hline $\mathrm{Si}_{24} \mathrm{Ge}_{33.3} \mathrm{Te}_{42.7}$ & Hexagonal Te, PDF 03-065-2270, s.g. P3121 (152) & 345.6 & 254.3 \\
\hline $\mathrm{Si}_{12.6} \mathrm{Ge}_{32.4} \mathrm{Te}_{55}$ & $\begin{array}{l}\text { Hexagonal Te, PDF 00-036-1452, s.g. P3121 (152) } \\
\text { Rhombohedral GeTe, PDF 00-047-1079, s.g. R3m (166) }\end{array}$ & 237.5 & 221.2 \\
\hline $\mathrm{Si}_{20.3} \mathrm{Ge}_{23.4} \mathrm{Te}_{56.3}$ & Hexagonal Te, PDF 00-036-1452, s.g. P3121 (152) & 253.7 & 217.5 \\
\hline $\mathrm{Si}_{8.8} \mathrm{Ge}_{33.1} \mathrm{Te}_{58.1}$ & $\begin{array}{l}\text { Rhombohedral GeTe, PDF 00-047-1079, s.g. R3m (166) } \\
\text { Hexagonal Te, PDF 00-036-1452, s.g. P3121(152) }\end{array}$ & 207.2 & 212.7 \\
\hline $\mathrm{Si}_{14.9} \mathrm{Ge}_{26.3} \mathrm{Te}_{58.8}$ & $\begin{array}{l}\text { Hexagonal Te, PDF 00-036-1452, s.g. P3121 (152) } \\
\text { Rhombohedral GeTe, PDF 00-047-1079, s.g. R3m (166) }\end{array}$ & 222.0 & 210.7 \\
\hline $\mathrm{Si}_{14.4} \mathrm{Ge}_{24.2} \mathrm{Te}_{61.4}$ & Hexagonal Te, PDF 04-007-5290, s.g. P3121 (152) & 204.9 & 203.8 \\
\hline $\mathrm{Si}_{17.5} \mathrm{Ge}_{19.7} \mathrm{Te}_{62.8}$ & Hexagonal Te, PDF 04-007-5290, s.g. P3121 (152) & 206.2 & 200.2 \\
\hline $\mathrm{Si}_{8.1} \mathrm{Ge}_{23.3} \mathrm{Te}_{68.6}$ & Hexagonal Te, PDF 04-007-5290, s.g. P3121 (152) & 142.1 & 184.5 \\
\hline $\mathrm{Si}_{11.8} \mathrm{Ge}_{19.5} \mathrm{Te}_{68.7}$ & Hexagonal Te, PDF 03-065-3370, s.g. P3121 (152) & 153.0 & 184.4 \\
\hline $\mathrm{Si}_{14.2} \mathrm{Ge}_{16} \mathrm{Te}_{69.8}$ & Hexagonal Te, PDF 04-007-5290, s.g. P3121 (152) & 153.7 & 181.4 \\
\hline
\end{tabular}

Table 2. Crystalline phases in the annealed $\mathrm{Si}-\mathrm{Ge}-\mathrm{Te}$ library and computed $T_{g}$ values. The crystalline phases formed after annealing at $400{ }^{\circ} \mathrm{C}$ and the glass transition temperatures, computed using the Lankhorst, $T_{g}^{L}$, and the Stochastic agglomeration model, $T_{g}^{S}$, for the prepared Si-Ge-Te library. The indicated compositions are measured in the center of each sample. Notation: s.g. = space group.

observed at 60 at $\%$ of Te, that suggests a transition to more ordered amorphous networks at the tie line between $\mathrm{Ge}_{2} \mathrm{Te}_{3}$ and $\mathrm{Si}_{2} \mathrm{Te}_{3}$. Two models, Lankhorst model and the stochastic agglomeration model, were used for the computation of the glass transition temperature. Annealing the library at $400{ }^{\circ} \mathrm{C}$ shows that all the samples crystallize, which confirms that the stochastic agglomeration model is more accurate in its predictions. Four groups of crystalline phases are identified which are positively correlated with the composition of the samples. Silicon does not take part in the formation of any crystalline phase up to $400{ }^{\circ} \mathrm{C}$ and remains in amorphous compounds. Its role is to delay or to prevent the crystallization of Te or GeTe. Above 60 at $\% \mathrm{Te}$, all the samples crystallize in hexagonal Te. These new findings in the $\mathrm{Si}-\mathrm{Ge}-\mathrm{Te}$ system enable a more informed and rapid decision making in material selection and design for applications in optical data storage, near-IR optical sensors and OTS devices.

\section{Methods}

The magnetron sputtering system consists of a cylindrical deposition chamber with semi-spherical up and down caps. Six magnetrons are equidistantly placed on the bottom semisphere. Three of these six magnetrons were simultaneously used to sputter the $\mathrm{Si}$, Ge and Te targets (99.99\% purity, Mateck $\mathrm{GmbH}$ ) and to obtain $\mathrm{Si}-\mathrm{Ge}-\mathrm{Te}$ combinatorial thin films. A set of substrates is placed on a holder in the upper part of the chamber. The distance between the central substrate and each magnetron is $11 \mathrm{~cm}$ (Fig. 9). Depositions with identical parameter settings were performed on graphite substrates for RBS measurements and on glass substrates for XRD and optical measurements. The deposition rates were optimized using an Inficon Q-bridge monitoring software connected to a quartz microcrystal. DC sputtering was used for the Ge and Si targets while RF sputtering was employed for the Te target. Powers between 10 and $50 \mathrm{~W}$ were applied on targets in order to obtain the targeted compositional range. Three series of depositions were performed and each time the deposition rate of Te was decreased in order to lower the Te concentration in the films. After initially evacuating the chamber to $10^{-6}$ Torr, Ar gas was introduced at a constant rate of $30 \mathrm{sccm}$, maintaining a stable pressure of $5 \times 10^{-3}$ Torr during deposition. The surface of the targets was cleaned before deposition for 5 min with the shutters covering the magnetrons. The substrates were held at room temperature during depositions. In order to obtain thin layers suitable for structural, morphological and optical investigations, a thickness between 300 and $600 \mathrm{~nm}$ was pursued, resulting in a deposition time between 1500 and 2000s. 

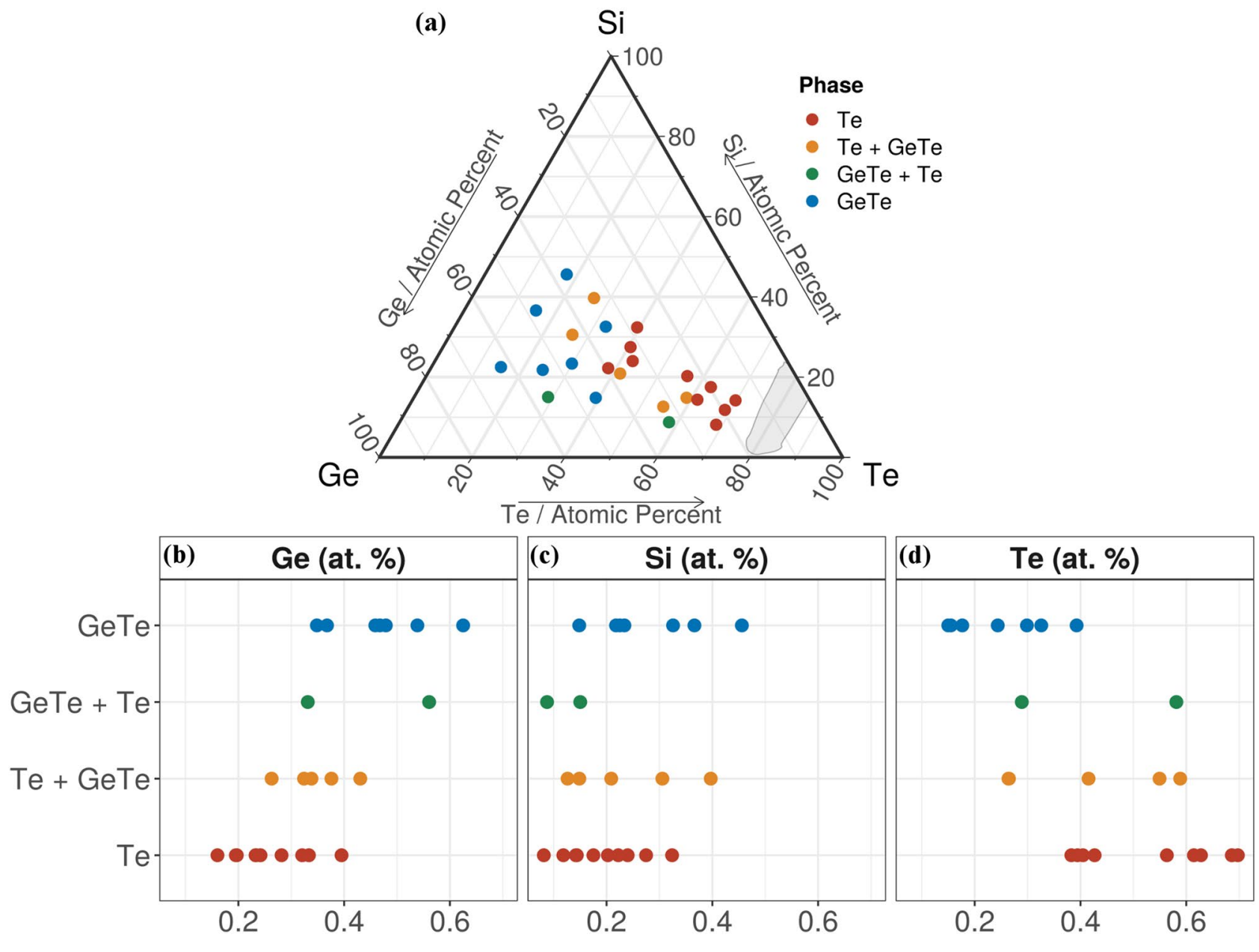

Figure 8. Crystalline phases formed after annealing the combinatorial library at $400{ }^{\circ} \mathrm{C}$. Crystalline phases shown as a function of (a) composition in the $\mathrm{Si}-\mathrm{Ge}-\mathrm{Te}$ ternary diagram; and elemental concentration of: (b) Ge; (c) Si and (d) Te. The ternary diagram in (a) was generated with the R software [v. 3.6.3] (R: A language and environment for statistical computing, R Core Team, R Foundation for Statistical Computing, Vienna, Austria (2020) http://www.R-project.org/.) using the package ggtern [v. 3.3.0] (https://cran.r-project.org/web/packages/ ggtern/index.html).

Rutherford backscattering spectrometry (RBS) experiments, using $3.041 \mathrm{MeV}$ alpha particles delivered by a 3 MV Tandetron ${ }^{62}$, were performed in order to measure the samples composition. The measurements were made using a backscattering angle of $165^{\circ}$. The backscattered particles were registered with an AMETEK type BU-012050-500 charged particle detector, having a solid angular acceptance of $1.641 \mathrm{msr}$, connected to a standard spectrometric chain and acquisition system. The typical energy resolution of the spectrometer was $18 \mathrm{keV}$. The RBS spectra were simulated using the SIMNRA software package ${ }^{63}$. The total combined standard uncertainty (accuracy) for each element is the following. For $\mathrm{Si}$ is $2.91 \%$ in the sample with the lowest $\mathrm{Si}$ concentration and $2.22 \%$ in the sample with the highest $\mathrm{Si}$ concentration, for Ge is $1.77 \%$ (lowest Ge concentration) and 1.26\% (highest Ge concentration) and for Te is $1.37 \%$ (lowest Te concentration) and $1.14 \%$ (highest Te concentration), respectively.

The structure of the samples was investigated by X-ray diffraction at grazing incidence (GIXRD) using $\mathrm{Cu}$ $\mathrm{K}_{\alpha}$ radiation $(\lambda=1.54178 \AA$ ) in a Rigaku SmartLab diffractometer, equipped with a HyPix-3000 2D Hybrid Pixel Array Detector (0D mode). The crystalline phases were identified using the DIFFRAC.EVA software. Only crystalline phases with a concentration above $5 \%$ were considered in the analysis.

Spectroscopic ellipsometry measurements were performed with a Woollam V-VASE system equipped with a HS- 190 monochromator, at incidence angles of $50^{\circ}, 60^{\circ}$ or $70^{\circ}$, in the spectral range $0.7-5 \mathrm{eV}$. A priori, the glass substrates were measured in order to model their dielectric functions and to verify the quality and reproducibility of the surfaces. The backside reflections were suppressed by using a translucent adhesive tape ${ }^{64}$. The experimental results obtained were fitted using a substrate/thin film optical model. The WVASE32 software was used to evaluate the dielectric constants following the procedures described in 'Guide to Using WVASE32'65. The complex dielectric function $(\varepsilon)$ is related to the refractive index, $n$, and extinction coefficient, $k$, through the direct measurement of changes in polarization $\psi$ and $\Delta$.

The imaginary part of the dielectric function is fitted using a Tauc-Lorentz oscillator model, $\varepsilon_{2}=\left(E-E_{g}\right)^{2} / E^{*}$ $A E_{0} \Gamma /\left[\left(E-E_{0}\right)^{2}+(\Gamma E)^{2}\right]^{50}$, where $E_{g}$ is the optical band gap, $E_{0}$ is the resonance or critical energy, $A$ is the amplitude and $\Gamma$ is the broadening of the oscillator. The real part of the dielectric function, $\varepsilon_{1}$, is related to $\varepsilon_{2}$ by the 


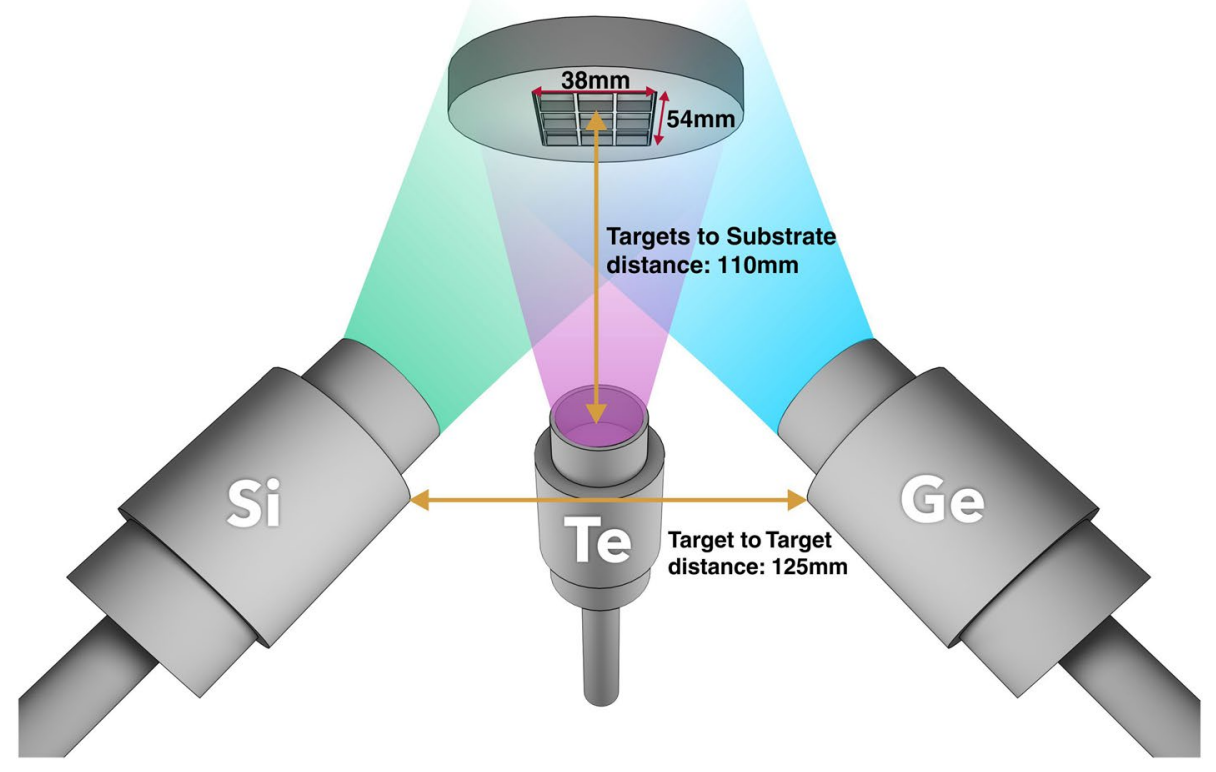

Figure 9. Schematic of the experimental combinatorial deposition setup. The three sputtering targets ( $\mathrm{Si}, \mathrm{Ge}$ and $\mathrm{Te}$ ) are equidistant $(125 \mathrm{~mm})$ and placed at a 45 degree angle with respect to the substrate surface. The substrates are placed in the center of a circular holder above the targets at a distance of $110 \mathrm{~mm}$. The figure was generated using 3ds Max 2020 (https://www.autodesk.com/) and CorelDRAW 11 (https://www.coreldraw.com/).

Kramers-Kronig relation. The optical dielectric constant, $\varepsilon_{\infty}$, is the low energy-limit of $\varepsilon_{1}$ and can be computed as $\varepsilon_{\infty}=\varepsilon_{1}(0.05 \mathrm{eV})^{66}$. The electronic transitions are described by the resonance energy $E_{0}$ of bound electrons oscillations, the broadening parameter $\Gamma$ representing the scattering time of the carriers and the amplitude $A$ given by the number of carriers making these transitions.

Annealing of the samples was performed in Ar atmosphere for $1 \mathrm{~h}$ at $400{ }^{\circ} \mathrm{C}$ using a MTI tubular furnace. We employ two models to estimate the glass transition temperature for the prepared library of compositions. The first model developed by Lankhorst ${ }^{56}$ computes $T_{g}$ based on bond enthalpies for glasses predominantly covalently bonded, using an empirical relation, $T_{g}=3.44{ }^{*} H_{a}-480$, where $H_{a}$ is the enthalpy of atomization obtained by summing all individual bond enthalpies. In the second simulation, the Stochastic agglomeration model ${ }^{57,58}$ is used, which is based on the Gibbs-DiMarzio $\operatorname{law}^{67}$ and estimates the changes in the glass transition temperature with the chemical composition. $T_{g}$ is computed as $T_{g}=T_{0} / \ln (2){ }^{\star} x+T_{0}$, where $T_{0}=T_{g}(x=0)$. $T_{0}$ was found by $\mathrm{K}$. Gunasekera et al. ${ }^{31}$ to be $373 \mathrm{~K}$, with $x$ being the atomic concentration of Ge or Si.

Received: 30 July 2020; Accepted: 21 May 2021

Published online: 03 June 2021

\section{References}

1. Wuttig, M. \& Yamada, N. Phase-change materials for rewritable data storage. Nat. Mater. 6, 824-832. https://doi.org/10.1038/ nmat2009 (2007).

2. Velea, A. et al. Te-based chalcogenide materials for selector applications. Sci. Rep. 7, 8103. https://doi.org/10.1038/s41598-01708251-z (2017).

3. Le Donne, A., Trifiletti, V. \& Binetti, S. New earth-abundant thin film solar cells based on chalcogenides. Front. Chem. 7, 297. https://doi.org/10.3389/fchem.2019.00297 (2019).

4. Eggleton, B. J., Luther-Davies, B. \& Richardson, K. Chalcogenide photonics. Nat. Photon. 5, 141-148. https://doi.org/10.1038/ nphoton.2011.309 (2011).

5. Thorpe, M. F. \& Tichý, L. Properties and Applications of Amorphous Materials (Springer, Dordrecht , 2001). https://doi.org/10.1007/ 978-94-010-0914-0.

6. Mott, N. F. \& Davis, E. A. Electronic Processes in Non-Crystalline Materials (Clarendon Press; Oxford University Press, Oxford, 1979).

7. Phillips, J. C. Structural principles of amorphous and glassy semiconductors. J. Non-Cryst. Solids 35-36, 1157-1165. https://doi. org/10.1016/0022-3093(80)90355-5 (1980).

8. Elliott, S. R. Physics of Amorphous Materials (Longman Scientific \& Technical, Hoboken, 1990).

9. Bureau, B., Boussard-Pledel, C., Lucas, P., Zhang, X. \& Lucas, J. Forming glasses from Se and Te. Molecules 14, 4337-4350. https:// doi.org/10.3390/molecules14114337 (2009).

10. Borisova, Z. U. Glassy Semiconductors (Springer, Boston, 1981). https://doi.org/10.1007/978-1-4757-0851-6.

11. Jóvári, P. et al. Short range order and stability of amorphous GexTe100-x alloys $(12 \leq \mathrm{x} \leq 44.6)$. J. Phys. Condens. Matter. $25,195401$. https://doi.org/10.1088/0953-8984/25/19/195401 (2013).

12. Tanaka, K. \& Shimakawa, K. Amorphous Chalcogenide Semiconductors and Related Materials (Springer, New York, 2011). https:// doi.org/10.1007/978-1-4419-9510-0. 
13. Green, M. L., Takeuchi, I. \& Hattrick-Simpers, J. R. Applications of high throughput (combinatorial) methodologies to electronic, magnetic, optical, and energy-related materials. J. Appl. Phys. 113, 231101. https://doi.org/10.1063/1.4803530 (2013).

14. Potyrailo, R. A. \& Mirsky, V. M. Combinatorial and high-throughput development of sensing materials: the first 10 years. Chem. Rev. 108, 770-813. https://doi.org/10.1021/cr068127f (2008).

15. Woods-Robinson, R. et al. Combinatorial tuning of structural and optoelectronic properties in Cu Zn1-S. Matter 1, 862-880. https://doi.org/10.1016/j.matt.2019.06.019 (2019).

16. Watanabe, M. et al. Combinatorial synthesis and high throughput evaluation of thermoelectric power factor in Mg-Si-Ge ternary compounds. Appl. Surf. Sci. 254, 777-780. https://doi.org/10.1016/j.apsusc.2007.05.095 (2007).

17. Koinuma, H. \& Takeuchi, I. Combinatorial solid-state chemistry of inorganic materials. Nat. Mater. 3, 429-438. https://doi.org/ $10.1038 /$ nmat1157 (2004).

18. Takeuchi, I., van Dover, R. B. \& Koinuma, H. Combinatorial synthesis and evaluation of functional inorganic materials using thin-film techniques. MRS Bull. 27, 301-308. https://doi.org/10.1557/mrs2002.97 (2002).

19. Han, Y. et al. Combinatorial nitrogen gradients in sputtered thin films. ACS Comb. Sci. 20, 436-442. https://doi.org/10.1021/acsco mbsci.8b00035 (2018).

20. Siol, S. et al. Combinatorial reactive sputtering of In $2 \mathrm{~S} 3$ as an alternative contact layer for thin film solar cells. ACS Appl. Mater. Interfaces 8, 14004-14011. https://doi.org/10.1021/acsami.6b02213 (2016).

21. Sava, F. et al. Secondary crystalline phases influence on optical properties in off-stoichiometric Cu2S-ZnS-SnS2 thin films. Materials 13, 4624. https://doi.org/10.3390/ma13204624 (2020).

22. Mokurala, K. et al. Combinatorial chemical bath deposition of CdS contacts for chalcogenide photovoltaics. ACS Comb. Sci. 18, 583-589. https://doi.org/10.1021/acscombsci.6b00074 (2016).

23. Bunn, J. K., Metting, C. J. \& Hattrick-Simpers, J. A semi-empirical model for tilted-gun planar magnetron sputtering accounting for chimney shadowing. JOM 67, 154-163. https://doi.org/10.1007/s11837-014-1234-2 (2015).

24. Mawale, R. et al. Amorphous Ge-Bi-Se thin films: a mass spectrometric study. Sci. Rep. 9, 19168. https://doi.org/10.1038/s41598019-55773-9 (2019).

25. Swallen, S. F. et al. Organic glasses with exceptional thermodynamic and kinetic stability. Science 315, 353-356. https://doi.org/ 10.1126/science.1135795 (2007).

26. Singh, S., Ediger, M. D. \& de Pablo, J. J. Ultrastable glasses from in silico vapour deposition. Nat. Mater. 12, 139-144. https://doi. org/10.1038/nmat3521 (2013).

27. Wang, Z., Du, T., Anoop Krishnan, N. M., Smedskjaer, M. M. \& Bauchy, M. On the equivalence of vapor-deposited and meltquenched glasses. J. Chem. Phys. 152, 164504. https://doi.org/10.1063/5.0006590 (2020).

28. Feltz, A., Maul, W. \& Schönfeld, I. Über Glasbildung und Eigenschaften von Chalkogenidsystemen. II. Zur Glasbildung in den Systemen As-Ge-Si-Te und Ge-Si-Te. Z. anorg. Allg. Chem. 396(1), 103-107 https://doi.org/10.1002/zaac.19733960112 (1973).

29. Lakshmi, K. P. \& Asokan, S. Electrical switching in amorphous Si-Te-Ge thin films: impact of input energy on crystallization process and switching parameters. J. Non-Cryst. Solids 377, 175-178. https://doi.org/10.1016/j.jnoncrysol.2013.02.010 (2013).

30. Anbarasu, M. \& Asokan, S. The influence of network rigidity on the electrical switching behaviour of Ge-Te-Si glasses suitable for phase change memory applications. J. Phys. D Appl. Phys. 40, 7515-7518. https://doi.org/10.1088/0022-3727/40/23/040 (2007).

31. Gunasekera, K., Boolchand, P. \& Micoulaut, M. Effect of mixed Ge/Si cross-linking on the physical properties of amorphous Ge-Si-Te networks. J. Appl. Phys. 115, 164905. https://doi.org/10.1063/1.4871780 (2014).

32. Cleveland, W. S. \& Devlin, S. J. Locally weighted regression: an approach to regression analysis by local fitting. J. Am. Stat. Assoc. 83, 596-610. https://doi.org/10.2307/2289282 (1988).

33. Hilton, A. R. Optical properties of chalcogenide glasses. J. Non-Cryst. Solids 2, 28-39. https://doi.org/10.1016/0022-3093(70) 90118-3 (1970).

34. Popescu, M., Velea, A., Sava, F. \& Lőrinczi, A. Chalcogenide systems at the border of the glass-formation domain: a key for understanding the memory-switching phenomena. Physica Status Solidi (b) 251, 1334-1339. https://doi.org/10.1002/pssb.201350104 (2014).

35. Popescu, M. \& Micoulaut, M. Rigidity and Boolchand Intermediate Phases in Nanomaterials (INOE Publishing House, Magurele, 2009).

36. Phillips, J. C. Topology of covalent non-crystalline solids I: short-range order in chalcogenide alloys. J. Non-Cryst. Solids 34, 153-181. https://doi.org/10.1016/0022-3093(79)90033-4 (1979).

37. He, H. \& Thorpe, M. F. Elastic properties of glasses. Phys. Rev. Lett. 54, 2107-2110. https://doi.org/10.1103/PhysRevLett.54.2107 (1985).

38. Chen, M., Rubin, K. A. \& Barton, R. W. Compound materials for reversible, phase-change optical data storage. Appl. Phys. Lett. 49, 502-504. https://doi.org/10.1063/1.97617 (1986).

39. Baudet, E. et al. Experimental design approach for deposition optimization of RF sputtered chalcogenide thin films devoted to environmental optical sensors. Sci. Rep. 7, 3500. https://doi.org/10.1016/10.1038/s41598-017-03678-w (2017).

40. Orava, J. et al. Optical properties and phase change transition in Ge2Sb2Te5 flash evaporated thin films studied by temperature dependent spectroscopic ellipsometry. J. Appl. Phys. 104, 043523. https://doi.org/10.1063/1.2970069 (2008).

41. Velea, A., Socol, G., Popescu, M. \& Galca, A. C. In-situ characterization of the optical and electronic properties in GeTe and GaSb thin films. J. Appl. Phys. 118, 135712. https://doi.org/10.1016/10.1063/1.4932666 (2015).

42. Tanaka, K. Transient-grating study of amorphous $\mathrm{As}_{2} \mathrm{~S}_{3}$ films. J. Appl. Phys. 65, 2042-2046. https://doi.org/10.1063/1.342872 (1989).

43. Srinivasan, A., Madhusoodanan, K. N., Gopal, E. S. R. \& Philip, J. Observation of a threshold behavior in the optical band gap and thermal diffusivity of Ge-Sb-Se glasses. Phys. Rev. B 45, 8112-8115. https://doi.org/10.1103/PhysRevB.45.8112 (1992).

44. Gamulin, O., Ivanda, M., Mitsa, V., Pašić, S. \& Balarin, M. Spectroscopy studies of structural phase transitions of chalcogenide glass thin films $(\mathrm{Ge} 2 \mathrm{~S} 3) \mathrm{x}(\mathrm{As} 2 \mathrm{~S} 3) 1-\mathrm{x}$ at coordination number 2.67. Solid State Commun. 135, 753-758. https://doi.org/10.1016/j. ssc.2005.05.006 (2005).

45. Vigreux, C. et al. Evidence of a minimum in refractive indexes of amorphous $\mathrm{Ge}_{\mathrm{x}} \mathrm{Te}_{100-\mathrm{x}}$ films: relevance to the development of infrared waveguides: evidence of a minimum in refractive indexes of amorphous $\mathrm{Ge}_{\mathrm{x}} \mathrm{Te}_{100-\mathrm{x}}$ films. Phys. Status Solidi A 211, 932-937. https://doi.org/10.1002/pssa.201330407 (2014).

46. Boolchand, P. et al. Nanoscale phase separation effects near and 2.67 , and rigidity transitions in chalcogenide glasses. C. R. Chim. 5, 713-724. https://doi.org/10.1016/S1631-0748(02)01440-6 (2002).

47. Fujiwara, H. \& Collins, R. W. Spectroscopic Ellipsometry for Photovoltaics: Volume 1: Fundamental Principles and Solar Cell Characterization Vol. 212 (Springer, Cham , 2018). https://doi.org/10.1007/978-3-319-75377-5.

48. Tanaka, K. Optical properties and photoinduced changes in amorphous AsS films. Thin Solid Films 66, 271-279. https://doi.org/ 10.1016/0040-6090(80)90381-8 (1980).

49. Ferlauto, A. S. et al. Analytical model for the optical functions of amorphous semiconductors from the near-infrared to ultraviolet: applications in thin film photovoltaics. J. Appl. Phys. 92, 2424-2436. https://doi.org/10.1063/1.1497462 (2002).

50. Jellison, G. E. \& Modine, F. A. Parameterization of the optical functions of amorphous materials in the interband region. Appl. Phys. Lett. 69, 371-373. https://doi.org/10.1063/1.118064 (1996).

51. Němec, P. et al. Ge-Sb-Te thin films deposited by pulsed laser: an ellipsometry and Raman scattering spectroscopy study. J. Appl. Phys. 106, 103509. https://doi.org/10.1063/1.3259435 (2009). 
52. Orava, J., Šik, J., Wágner, T. \& Frumar, M. Optical properties of As33S67-xSex bulk glasses studied by spectroscopic ellipsometry. J. Appl. Phys. 103, 083512. https://doi.org/10.1063/1.2906138 (2008).

53. Shportko, K. et al. Resonant bonding in crystalline phase-change materials. Nat. Mater. 7, 653-658. https://doi.org/10.1038/nmat2 226 (2008).

54. Littlewood, P. B. The dielectric constant of cubic IV-VI compounds. J. Phys. C: Solid State Phys. 12, 4459-4468. https://doi.org/ $10.1088 / 0022-3719 / 12 / 21 / 013(1979)$.

55. Kalb, J. A., Wuttig, M. \& Spaepen, F. Calorimetric measurements of structural relaxation and glass transition temperatures in sputtered films of amorphous Te alloys used for phase change recording. J. Mater. Res. 22, 748-754. https://doi.org/10.1557/jmr. 2007.0103 (2007).

56. Lankhorst, M. H. R. Modelling glass transition temperatures of chalcogenide glasses. Applied to phase-change optical recording materials. J. Non-Cryst. Solids 297, 210-219. https://doi.org/10.1016/S0022-3093(01)01034-1 (2002).

57. Naumis, G. G. Variation of the glass transition temperature with rigidity and chemical composition. Phys. Rev. B 73, 172202. https://doi.org/10.1103/PhysRevB.73.172202 (2006).

58. Micoulaut, M. The slope equations: a universal relationship between local structure and glass transition temperature. Eur. Phys. J. B 1, 277-294. https://doi.org/10.1007/s100510050184 (1998).

59. Koo, Y., Lee, S., Park, S., Yang, M. \& Hwang, H. Simple binary ovonic threshold switching material site and its excellent selector performance for high-density memory array application. IEEE Electron. Dev. Lett. 38, 568-571. https://doi.org/10.1016/10.1109/ LED.2017.2685435 (2017).

60. Petersen, K. E., Birkholz, U. \& Adler, D. Properties of crystalline and amorphous silicon telluride. Phys. Rev. B 8(4), 1453-1461. https://doi.org/10.1103/PhysRevB.8.1453 (1973).

61. Zhang, S. N., Zhu, T. J. \& Zhao, X. B. Crystallization kinetics of $\mathrm{Si}_{15} \mathrm{Te}_{85}$ and $\mathrm{Si}_{20} \mathrm{Te}_{80}$ chalcogenide glasses. Phys. B 403, 3459-3463 (2008).

62. Burducea, I. et al. A new ion beam facility based on a 3 MV Tandetron at IFIN-HH, Romania. Nucl. Instrum. Methods Phys. Res., Sect. B 359, 12-19. https://doi.org/10.1016/j.nimb.2015.07.011 (2015).

63. Mayer, M. SIMNRA User's Guide Technical Report IPP 9/133, MPI für Plasmaphysik, Garching, Germany. http://home.rzg.mpg. de/ mam/index.html (1997).

64. Synowicki, R. A. Suppression of backside reflections from transparent substrates. Phys. Stat. Sol. c 5, 1085-1088. https://doi.org/ $10.1002 /$ pssc. 200777873 (2008).

65. Woollam Co. Inc., J.A. Guide to Using WVASE32, (Lincoln, NE, USA, 1996).

66. Galca, A. C. et al. Structural and optical properties of optimized amorphous GeTe films for memory applications. J. Non-Cryst. Solids 499, 1-7. https://doi.org/10.1016/j.jnoncrysol.2018.07.007 (2018).

67. Debenedetti, P. G. Metastable Liquids (Princeton University Press, Princeton, 1996).

\section{Acknowledgements}

Authors kindly acknowledge the financial support of the Romanian Ministry of Research and Innovation in the framework of the TE 62/2018 project and POC-G 54/2016 MAT2IT, contract no. 1550/2018. Ion beam experiments have been performed at 3 MV Tandetron accelerator from "Horia Hulubei" National Institute for Physics and Nuclear Engineering (IFIN-HH) and were supported by the Romanian Governmental Programme through the National Programme "Instalații şi Obiective de Interes Naţional".

\section{Author contributions}

A.V. and C.M. conceived this study. I.D.S. performed materials library deposition and thermal treatment. F.S. executed the XRD measurements and crystalline phases identifications. A.C.G. conducted the assessment of the optical properties of the library by spectroscopic ellipsometry and applied the optical models to extract the optical constants. I.B. carried RBS measurements and RBS data processing. N.B. upgraded and ensured proper operation of the deposition equipment. C.M. built the database with the results, performed the statistical analysis and generated the figures. A.V. and C.M. wrote the article, all other authors contributed to the discussion of the results and to the manuscript improvement.

\section{Competing interests}

The authors declare no competing interests.

\section{Additional information}

Supplementary Information The online version contains supplementary material available at https://doi.org/ 10.1038/s41598-021-91138-x.

Correspondence and requests for materials should be addressed to A.V.

Reprints and permissions information is available at www.nature.com/reprints.

Publisher's note Springer Nature remains neutral with regard to jurisdictional claims in published maps and institutional affiliations.

Open Access This article is licensed under a Creative Commons Attribution 4.0 International License, which permits use, sharing, adaptation, distribution and reproduction in any medium or format, as long as you give appropriate credit to the original author(s) and the source, provide a link to the Creative Commons licence, and indicate if changes were made. The images or other third party material in this article are included in the article's Creative Commons licence, unless indicated otherwise in a credit line to the material. If material is not included in the article's Creative Commons licence and your intended use is not permitted by statutory regulation or exceeds the permitted use, you will need to obtain permission directly from the copyright holder. To view a copy of this licence, visit http://creativecommons.org/licenses/by/4.0/.

(C) The Author(s) 2021 